Article

\title{
Late Pleistocene and Early Holocene Rock Art from the Mongolian Altai: The Material and its Cultural Implications
}

\author{
Esther Jacobson-Tepfer \\ Department of Art History, University of Oregon Eugene, OR 97403-5229 USA ; E-Mail: \\ ejacobs@uoregon.edu; Tel.: +1-541-344-3497
}

Received: 9 August 2013; in revised form: 10 September 2013 / Accepted: 11 September 2013 /

Published: 18 September 2013

\begin{abstract}
Rock-pecked images from the northern Mongolian Altai attest to the presence of human communities within the high valleys of that region during the Late Pleistocene and Early Holocene. The material provides evidence that is hitherto largely missing from the archaeological record of that region. This paper reviews the rock art, its find sites and larger physical contexts and uses evidence from paleoenvironmental studies to propose dating and cultural significance. The material is compared with other sites said to have Paleolithic imagery from Mongolia and the adjoining Russian Altai. The body of presented material offers a major resource for the study of early hunter-gatherer communities at the interface of Central and North Asia.
\end{abstract}

Keywords: Pleistocene; Holocene; Paleolithic; Mesolithic; mammoth; rhinoceros; ostrich; aurochs; Altai Mountains; Mongolia

\section{Introduction}

Tsagaan Salaa II (TS II) is part of the huge Tsagaan Salaa-Baga Oigor (TS-BO) petroglyphic complex in northwestern Mongolia (Map 1). Rising above the north bank of the Tsagaan Salaa River, the slopes of TS II are steep and covered with boulders and outcrops. One outcrop, near the section's ridgeline, is now almost completely fractured. Its few intact surfaces are scraped and polished, distantly reflecting the action of the ancient glaciers that filled the Tsagaan Salaa valley in the late Pleistocene up to an elevation of at least $200 \mathrm{~m}$. Two images appear on these fragments. One of a wild mountain sheep known as argali is visible on the south edge of the outcrop while on the north side is found an image of uncertain identity (Figure 1). Despite their shared location, the images are as 
different in conception and execution as they are in type. Although unfinished, the argali is executed in a naturalistic manner. By contrast, the massive body of the second has been defined by a roughly pecked contour of uneven width. The animal's legs are almost vestigial—its front legs indicated by a wide band while its hind legs are indicated by a short, inverted cone shape. The animal has neither horns nor antlers; this lack suggests that it, also, was never finished. While the argali bears the marks of an early Bronze Age date, the unidentified animal of TS II can be described as archaic in appearance and execution.

Map 1. Complex Sections, Tsagaan Salaa-Baga Oigor Petroglyphic Complex, Bayan Ölgiy, Mongolia.

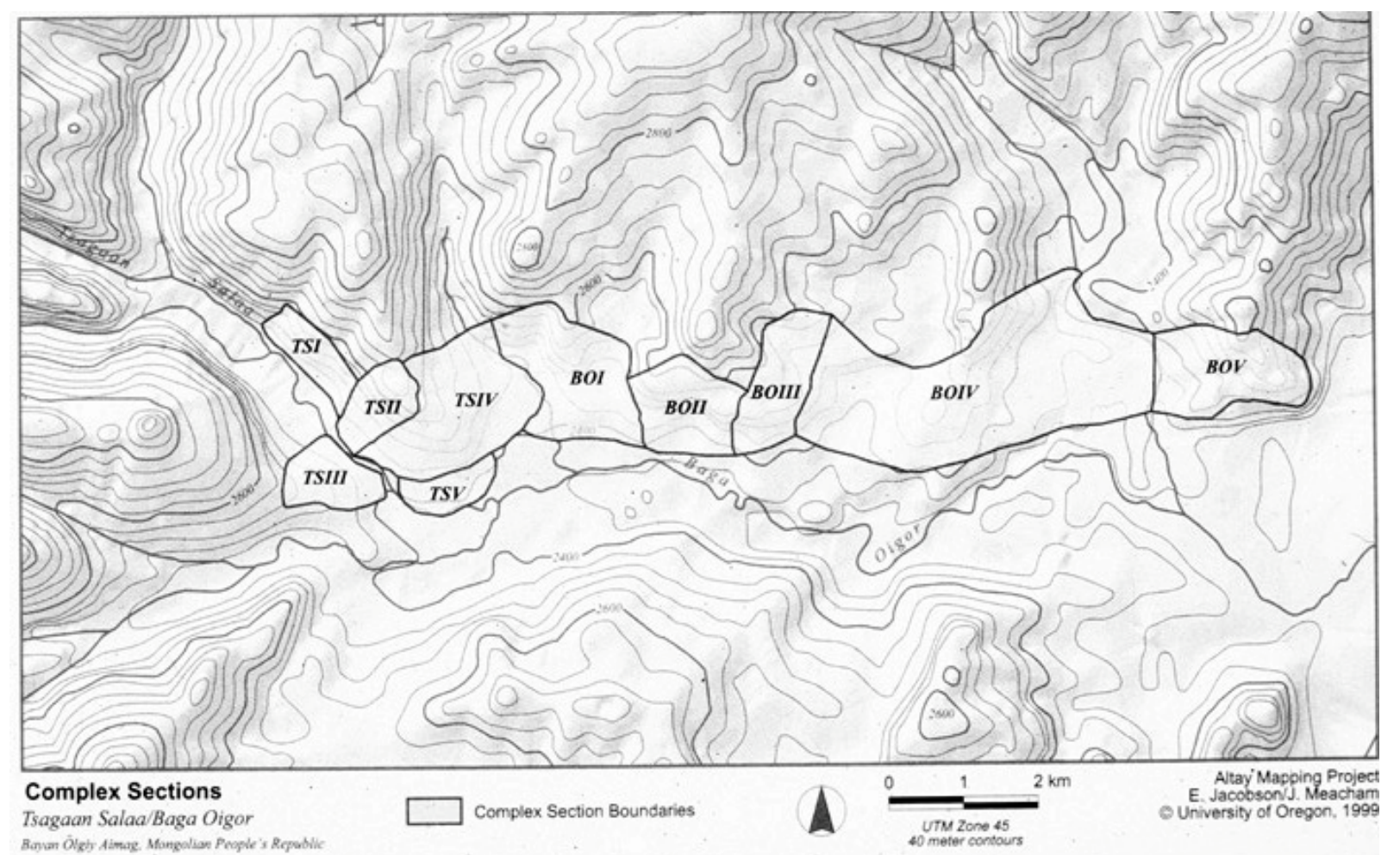

Figure 1. Unidentified animal, Tsagaan Salaa II (http://oregondigital.org/u?maic,714).

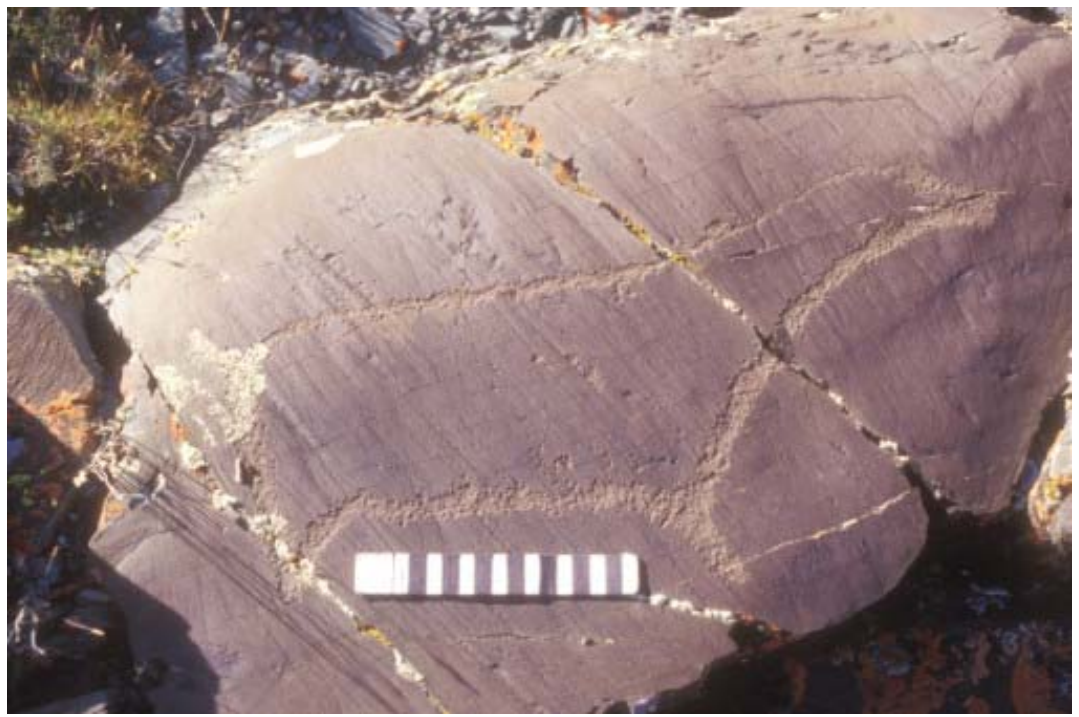


Similarly archaic in appearance are many other images in the Mongolian Altai. This simple image thus raises a number of questions. What criteria may we confidently use to distinguish rock-pecked imagery of the Altai Mountains dating to a period earlier than the Bronze Age? How can we determine whether that material belongs to the late Pleistocene and early Holocene epochs? Across which sites is the relevant imagery located and how do those sites relate to the larger physical context? Considered within its physical and paleoenvironmental contexts, can this material illuminate the history of human culture in the mountainous heart of Eurasia? In raising and pursuing these questions, I wish the reader to bear in mind a number of qualifications regarding the identification of the animals represented and the dates to which they are assigned. In all cases, identification is based on my carefully considered judgment formed from extensive experience with these and hundreds of comparative images and, in many cases, with those animal species that have survived to the present. In addition, I have not hesitated to turn to scientific authority to support my hypotheses regarding species identification. To a certain extent, of course, dating is subjective; but where there are clear correlations between species and constraining environmental conditions (as discussed extensively below), tentative dates are, I believe, justified. Finally, in the vast majority of cases referred to here, the stone on which the images are pecked is metagreywacke (sandstone).

\section{Geographical and Cultural Contexts}

The body of rock-pecked imagery to be considered here is located in the Altai Mountains of northwestern Bayan Ölgiy aimag, where Mongolia meets the southern edge of Russia’s Altai Republic and northern China (Map 2). The relevant concentrations of rock art include the small site of Aral Tolgoi [1] and the large complexes of Upper Tsagaan Gol (sometimes referred to as Shiveet Khairkhan) [2] and Tsagaan Salaa-Baga Oigor [3]. With the exception of the animal from TS II, the images to be considered here are specific with regard to faunal species. Moreover, with reference to their technique of execution and style of presentation they differ radically from well-known and documented rock art of the Bronze Age or even that associated with a Neolithic or Eneolithic period. The following pages will document these assertions; but it is necessary to first state an equally absolute qualification. Although a vast amount of work has been done on Epipaleolithic and Neolithic sites in South Siberia [4-6], northern and eastern Mongolia and the Mongolian Gobi region [7], there has to date been no relevant published documentation of such sites within the Mongolian Altai. The closest relevant sites are all found a considerable distance away, in the Katun and Biya river drainages of the Russian Altai $[4,5,8]$. This does not mean that analogous Mongolian sites do not exist. On the contrary, even cursory surveys by the author and colleagues have revealed considerable evidence of Paleolithic habitation along the Khovd River as well as in all the high valleys referred to here-those of Aral Tolgoi, Tsagaan Gol, and Baga Oigor. This evidence includes a range of artifacts including scrapers, points, blades, nuclei and microblades; all artifacts, however, lay on the surface of the ground, testimony to the extreme deflation of cultural layers in this part of the world. In short, at the moment it is not possible to reconstruct an Upper Paleolithic, Mesolithic and Neolithic stratigraphy within this region on the basis of excavated artifacts and settlement patterns. On the other hand, the northern Mongolian Altai offers one of the richest resources for the study of rock art in North Asia and also one 
of the best preserved. The oldest material from that tradition illuminates early human culture in this heartland of Eurasia.

Map 2. Selected Rock Art Complexes of the Northern Mongolian Altai.

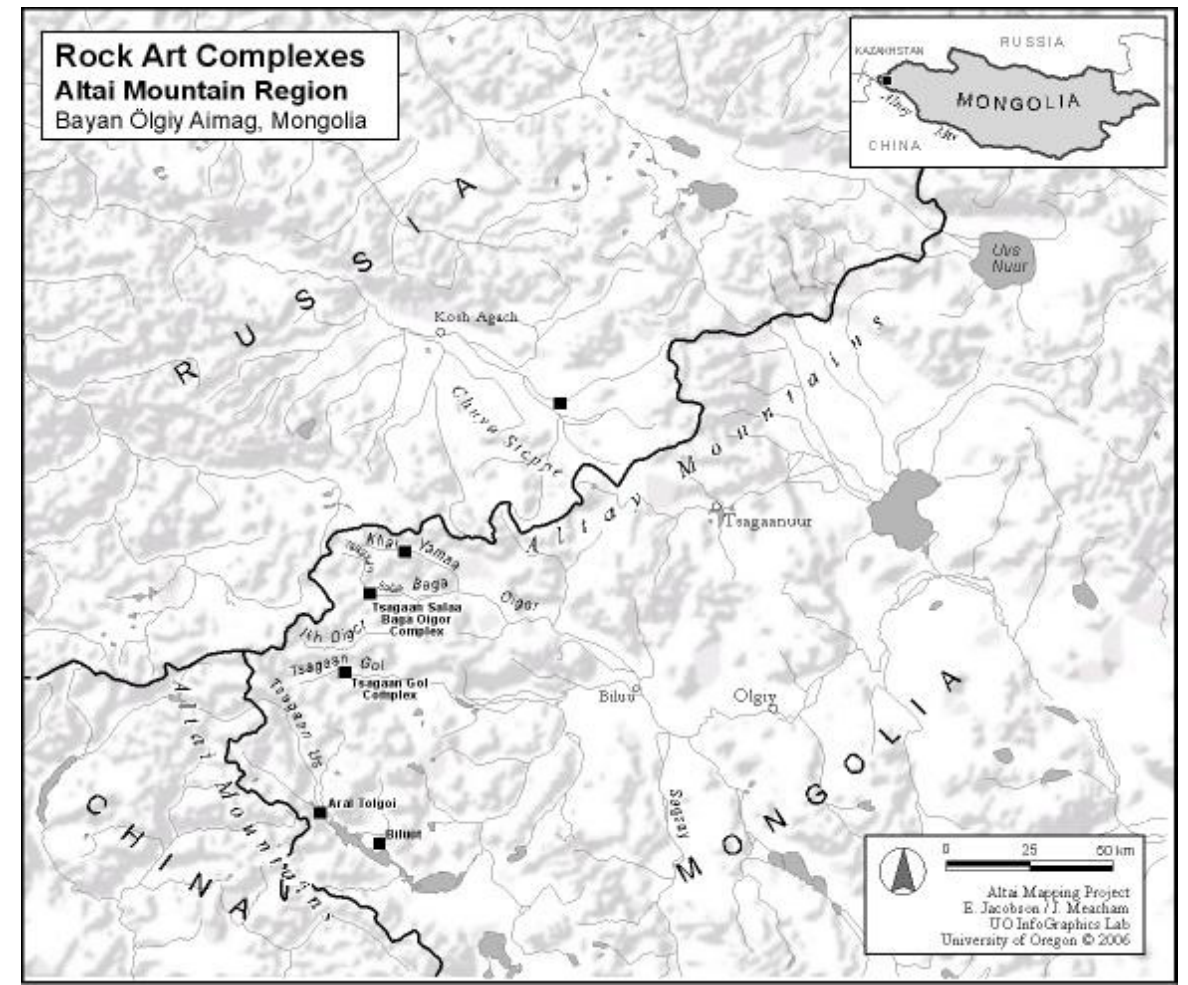

\section{Methods, Discussion}

\subsection{Traditional Approaches to the Dating of Petroglyphic Imagery}

Scholars have used a number of approaches to the dating of rock pecked imagery with varying success. Some have attempted to infer the dating of stone images on the basis of excavated materials in the immediate vicinity; but there is no necessary connection between the two. Indeed, the dating of organic materials recovered from nearby burials or ritual structures can be quite misleading. No less problematic is the frequent tendency to use materials gathered from ethnographically attested cultures to both date and explain imagery. Direct dating of petroglyphic imagery is also of dubious value. The exploitation of organic materials embedded within an image's pecked area-what one scholar has referred to as the "intra-coating detritus" [9]—offers no good assistance in dating an image. Cemented, as it may be within the microlaminations of the rock surface-or even within the pecked areas of a particularly old image - that material is notoriously capable of offering corrupted dates. No more certain are the bacterial materials associated with iron/manganese oxyhydroxide encrustations that gradually develop on stone surfaces under specific climatic conditions [10] since these, also, involve substances from vastly different periods. In effect, the organic matter deposited within the grooves of an image or the bacterial accumulations on the surface of the stone could significantly pre-date or post-date that image.

Some scholars have resorted to the relative darkness of patina and surface weathering in order to propose a hypothetical age for a particular image. Within the Mongolian Altai, such attempts are not 
reliable. Careful examination of the vast number of ornamented surfaces within the large complexes of that region makes clear that patina is as much a function of mineralization of the stone, surface tension (i.e., the slant of the surface), adjoining vegetation and proximity to moisture as it is a function of age. Images from the early Iron Age found on a vertical surface can be as light as images done in the Turkic period [11] or, because of the slant of their rock surface they can reflect the process of re-patination that occurred over a long period of time [12]. Far more useful is the observation of overlaid images, the differences in their re-patination and the cultural indicators of detail. In many cases, indeed, those layers of imagery are decisive indicators of relative dating. There are few such cases involving archaic imagery, but one surface from Baga Oigor II (BO II) offers a useful example of how even in such cases one must look very carefully to understand the overlay in detail (Figure 2).

Figure 2. Archaic aurochs overlaid by Iron Age goats. Baga Oigor II. (http://boundless.uoregon.edu/u?/maic,1076).

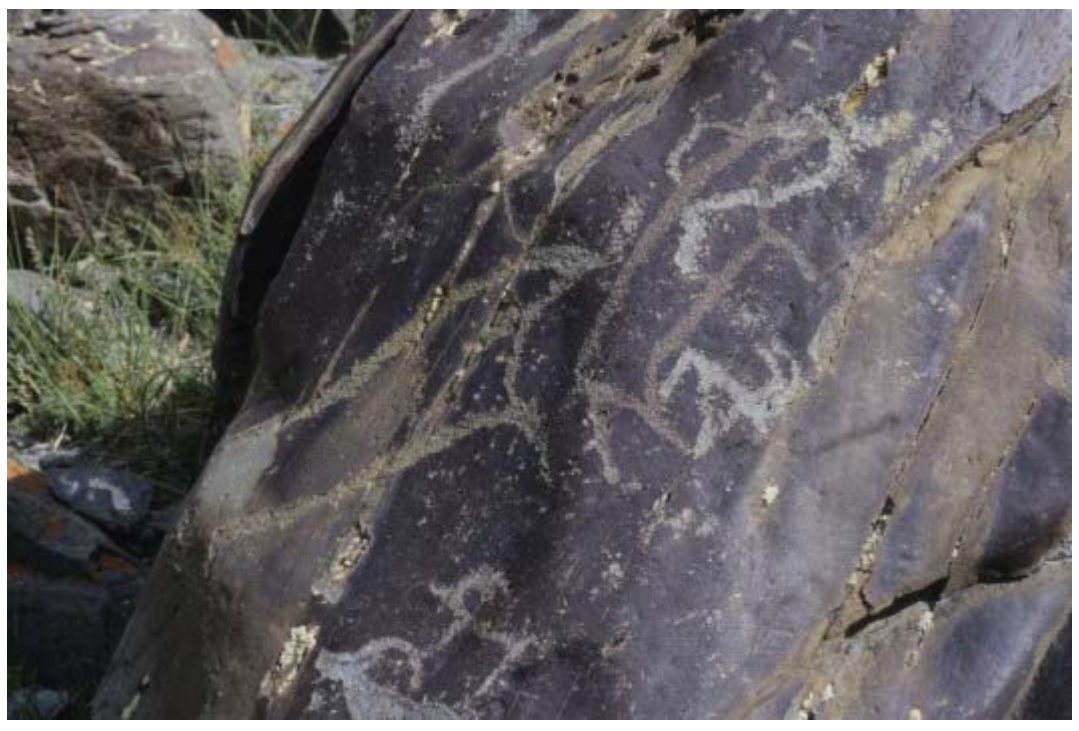

The consideration of techniques used to execute an image is a potentially more reliable indicator of period on a gross scale. Within the Altai complexes, petroglyphic images from the Bronze and Iron Ages are occasionally executed with direct, rough blows, but far more typical is an execution indicative of indirect pecking with a finely tipped tool and with a preference for silhouette or partial silhouette [13]. For example, in a composition from the Upper Tsagaan Gol's SK_H7 both the stag and the older bull over which it was pecked (Figure 3) reflect the kind of dense, controlled technique one comes to expect in imagery from the Bronze Age. In this case, overlay and relative patina are useful in deducing relative dating. Even in compositions that appear to date from the middle Bronze Age, one finds an extreme refinement of pecking, the use of indirect rather than direct blows and a preference for silhouette rather than complete contour. 
Figure 3. Stag (Late Bronze Age) pecked over Bronze Age bull. Upper Tsagaan Gol. (http://oregondigital.org/u?/maic,2208).

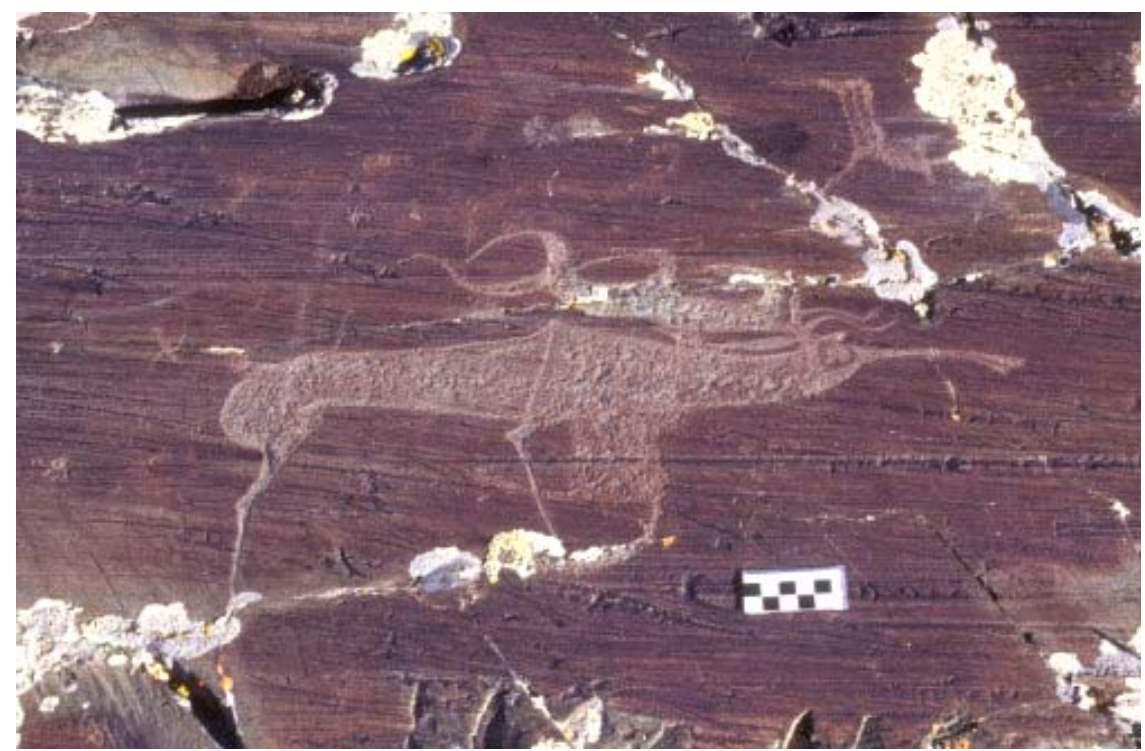

By contrast, there is no variation in the execution of petroglyphic images here assigned to the Paleolithic-Mesolithic period: like the unidentified animal from TS II, they are usually if not always represented with contour lines executed by direct blows. As a result, the pecked marks are frequently deep and uneven in distribution, and the contour edges are rough. This is clearly visible in the image of an unfinished aurochs from Aral Tolgoi (AT_24) (Figure 4). There are occasional exceptions to the contour rule, most particularly in the case of representations of aurochs, where the head may be rendered in silhouette form and the body in contours. However, in many of those cases (e.g., Figure 5), the extreme roughness of the pecking and the simplification of the animal's body reflect an archaic production.

Figure 4. Unfinished aurochs on scraped and polished outcrop. Pre-Bronze Age (Paleolithic period). Aral Tolgoi. (http://boundless.uoregon.edu/u?/maic,599).

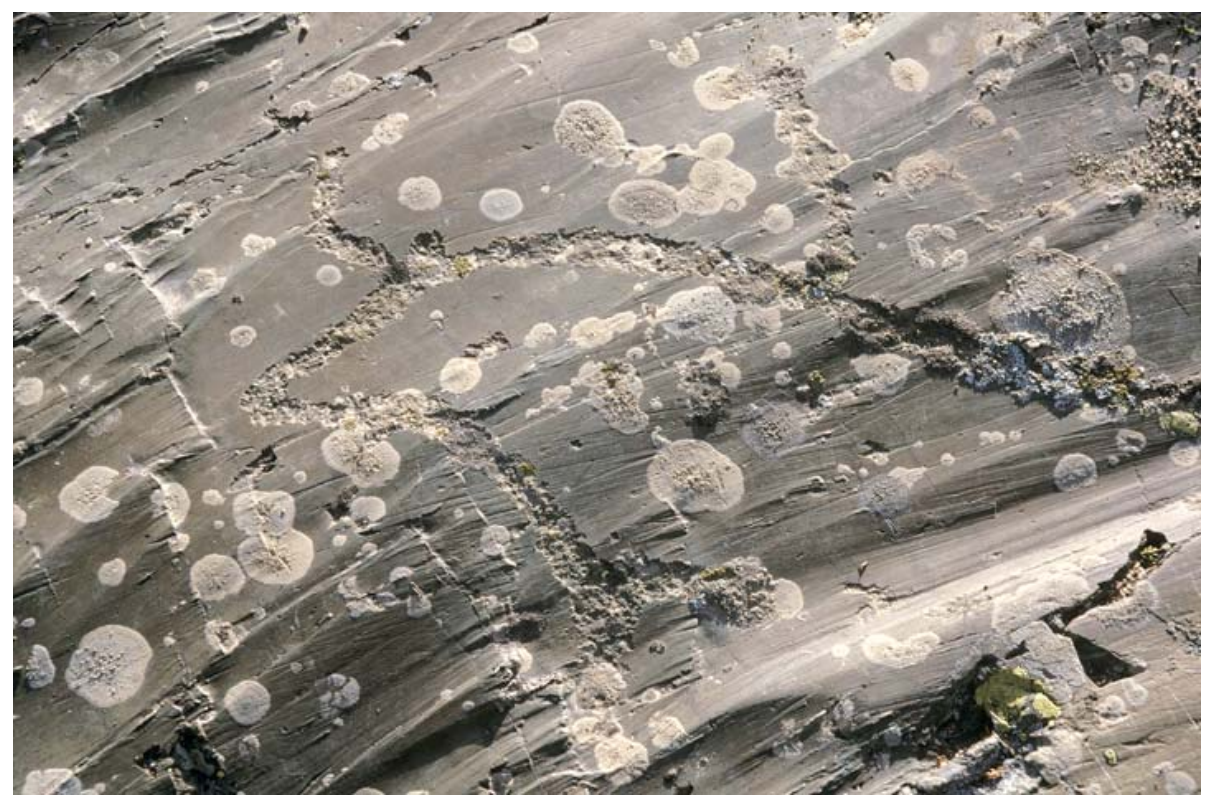


Figure 5. Aurochs. Pre-Bronze Age (Paleolithic period). Baga Oigor II. (http://oregondigital.org/u?/maic, 1088).

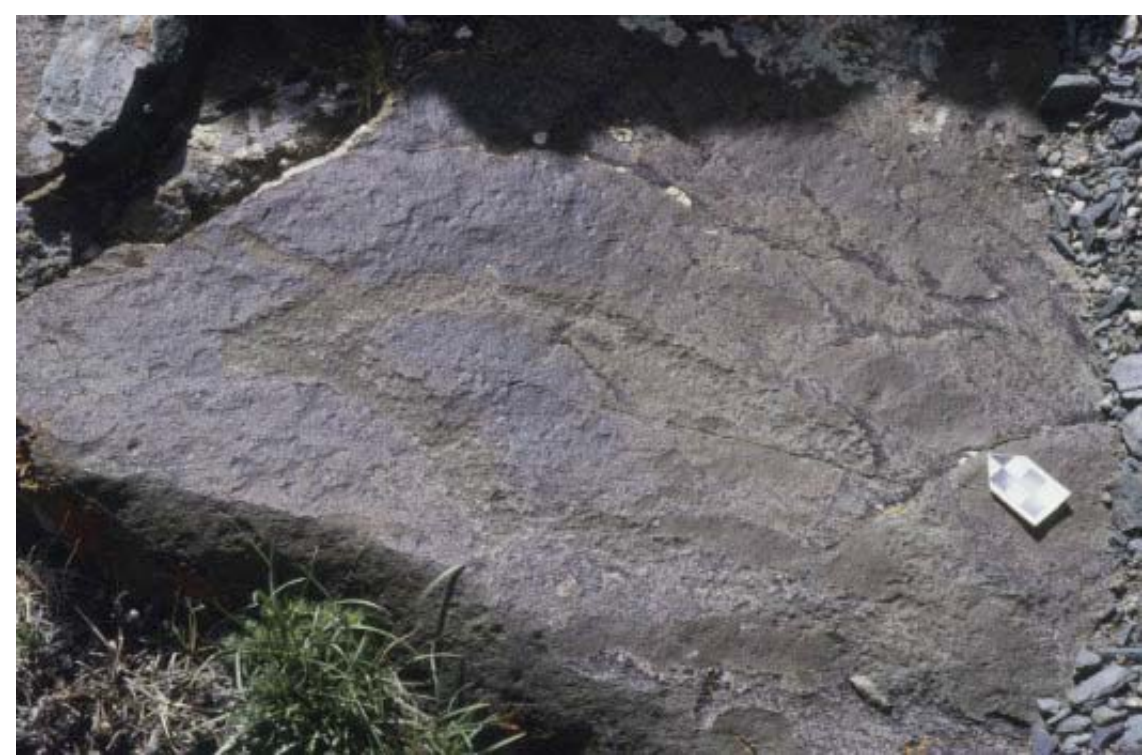

Beyond the manner of its execution, the unidentified animal of TS II indicates aspects of style that are always characteristic of archaic imagery in the Mongolian Altai, although they may also appear in the case of later images. These characteristics include a massive body that conveys the animal's physical presence. This is well illustrated by the superb aurochs from AT_24 (Figure 4) mentioned above: although the image is only partial, the treatment of the animal's powerful neck, deep chest and thrusting head conveys strength combined with grace. Other diagnostic characteristics are a static posture and the complete absence of any indication of psychological activity or response even when there are two or more animals on a surface. This is apparent in a group of large profile elk from Tsagaan Salaa III (TS III) (Figure 6). It is clearly indicated on a surface from AT_16 where the body of a long, elegant elk is crossed by that of an argali (Figure 7). In this case, as in the case of an aurochs juxtaposed with an inverted horse, from AT_22 (Figure 8), the animals evince no relationship one to the other despite their juxtaposition or overlay. All these images belong to a period that significantly predated the Bronze Age; more precisely (as will be shown) they may be assigned to the late Pleistocene or to the Pleistocene-early Holocene transition.

\subsection{The Dating of Imagery in Light of Paleoenvironmental Constraints: Tsagaan Salaa-Baga Oigor}

The last set of indicators that can and must be used to constrain the dating of any pre-Bronze Age imagery involves the consideration of contemporaneous vegetation and climate. This information is absolutely critical. It tells us when environmental conditions were supportive of certain animals and when those conditions had changed leading to the disappearance of certain animals and the appearance of others. In this respect, however, our unidentified animal from TS II (Figure 1) is mute: we cannot say whether it is an unfinished aurochs or any other animal, and its placement on a ruined outcrop tells us only that the image was pecked at some time after the passing of the last large glaciers in the valley. But that, of course, is unremarkable. The last glacial advance within the high valleys of the Mongolian Altai scraped all the bedrock down to the matrix, erasing any earlier images-if they had even existed. 
Figure 6. Two contoured elk and an ibex on scraped surface. Pre-Bronze Age. Tsagaan Salaa III. (http://oregondigital.org/u?/maic,774).

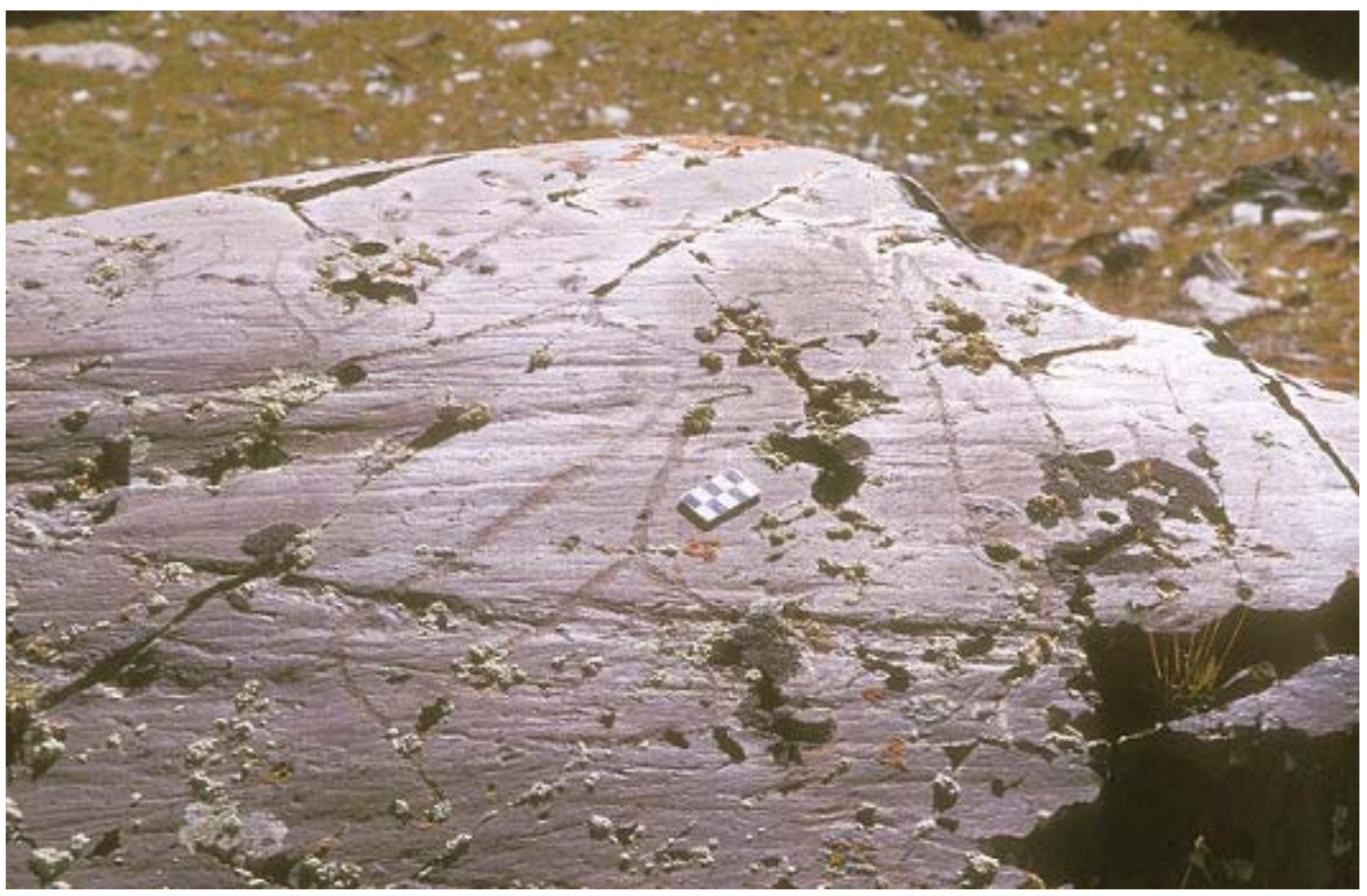

Figure 7. Elk overlaid by an argali. Pre-Bronze Age. Aral Tolgoi. (http://oregondigital.org/u?/maic,2104).

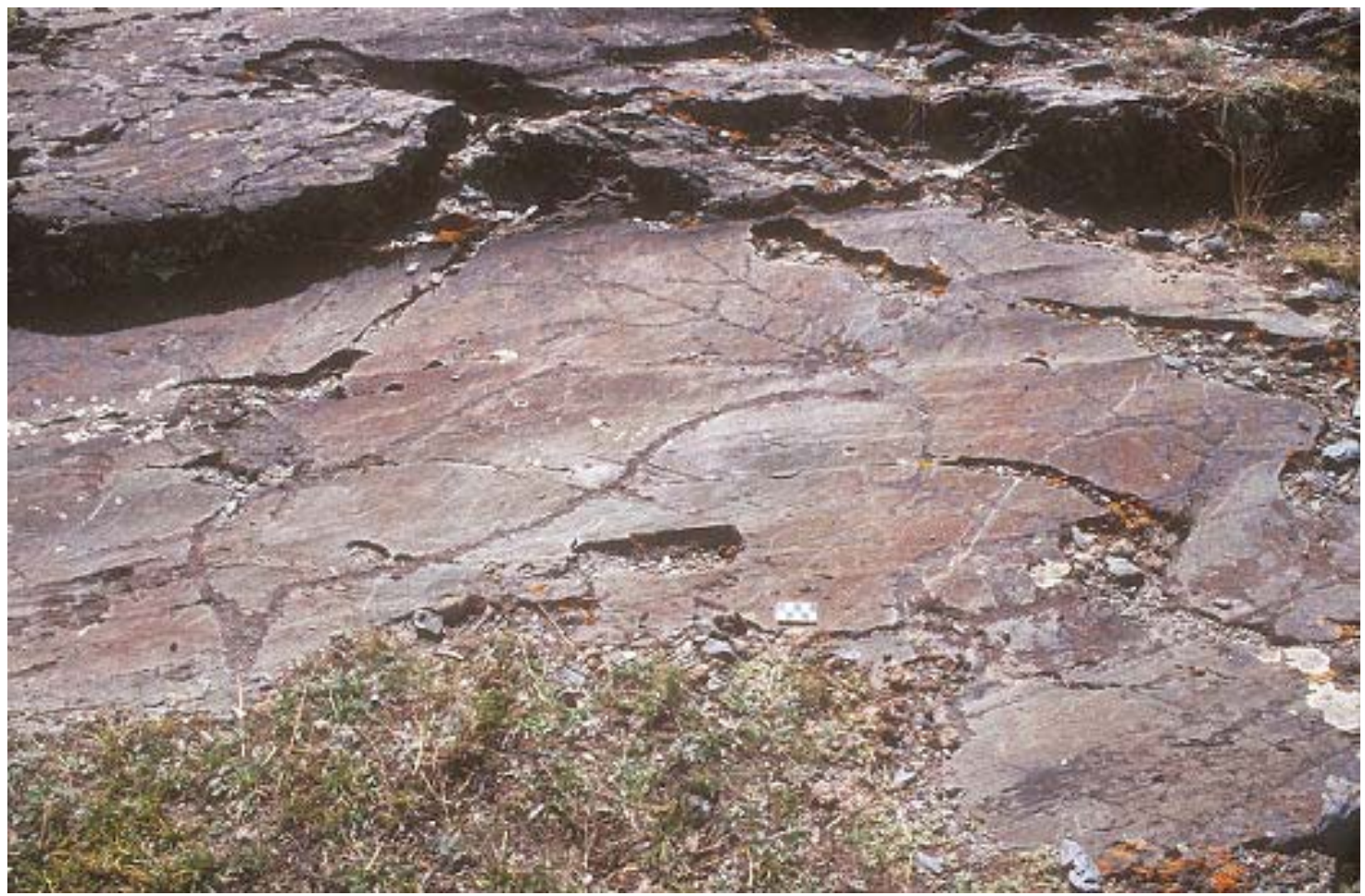


Figure 8. Aurochs and horse on fractured surface. Pre-Bronze Age. Aral Tolgoi. (http://oregondigital.org/u?/maic,2132).

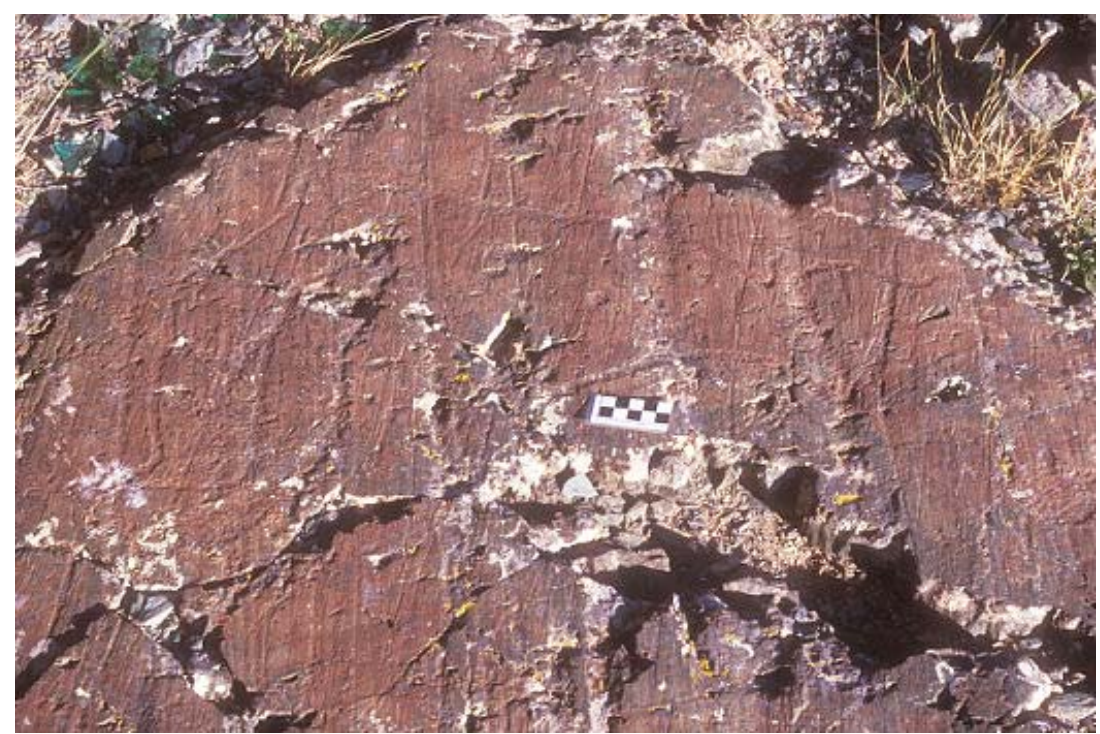

The consideration of paleoenvironmental issues may be approached through the archaic imagery of Tsagaan Salaa-Baga Oigor. This material is not distributed evenly across the complex as is, for example, imagery from the full and late Bronze Age. Instead one finds pockets of archaic images (Map 3). With the exception of the unidentified animal of TS II the images are concentrated on the terraces just above the former riparian zone. These concentrations include TS I, scattered surfaces in TS III; the west end of Tsagaan Salaa IV (TS IV) and adjoining sections of Tsagaan Salaa V (TS V); and along the terrace between BO II and the west end of Baga Oigor IV (BO IV). For the most part, then, the archaic images suggest temporary encampments along the lowest terraces over the edge of steppe and marsh.

Map 3. Distribution of archaic (Pre-Bronze Age) imagery. Tsagaan Salaa-Baga Oigor Complex.

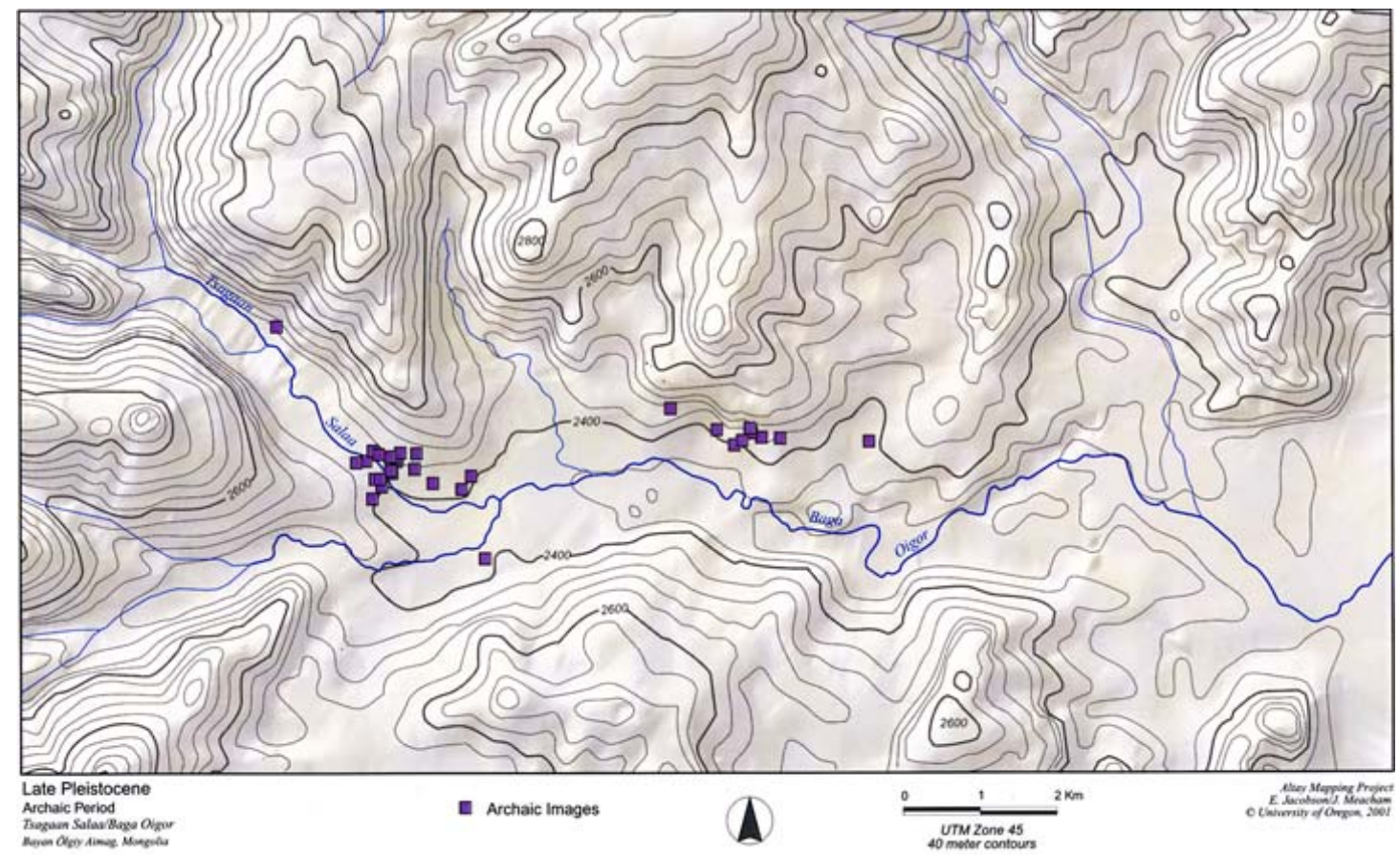


The present-day aspect of the Tsagaan Salaa and Baga Oigor valleys offers little information to indicate there had ever been another environment than what is now visible. The landscape is entirely treeless, the slopes covered with rough grasses and the valley floor characterized by a stony plain broken by occasional marshy areas. The obvious scrape and polish of bedrock up almost to the ridge tops on either side of the valleys recreates the presence of valley glaciers during the late Pleistocene. The Last Glacial Maximum (LGM) in this part of Asia is dated to 21.3-19.0 kya [14], but exactly when valley glaciation came to an end or even whether valley glaciation continued sporadically into the Early Holocene remains unclear $[15,16]$. Seen from high on the slopes or in aerial or satellite imagery, the contours of the valleys reveal traces of significant water erosion in an ancient period and even low dikes and moraines indicative of local and cataclysmic floods [17]. Such events are also reflected in several surfaces and boulders, particularly around the area where the Tsagaan Salaa enters the valley of the Baga Oigor. For example, a worn boulder lies at the northern edge of TS V and on the side of a plain in which are still visible the scour marks and shoreline of heavy, fast moving water [17]. The boulder (Figure 9) was clearly torn out of an original setting higher in the valley and carried along by water until it was deposited here. On the side of the inverted boulder are two archaic images: a large bear-like animal and a horse. Two other boulders at the mouth of the Tsagaan Salaa River reflect a major flood, possibly sudden but continuing for some duration and catalyzed, perhaps, as a result of the breaking of an ice dam at the point where the river enters the larger valley. One boulder, decorated with the worn images of horses and argali, has clearly been smoothed by the passage of water [18]. Another had been almost entirely buried in silt. Uncovering it revealed an image of an elk that on the basis of style would date to the early Bronze Age (Figures 10 and 11).

Figure 9. Inverted bear and horse on tumbled boulder. Pre-Bronze Age (Paleolithic period). Tsagaan Salaa V. (http://oregondigital.org/u?/maic,1477).

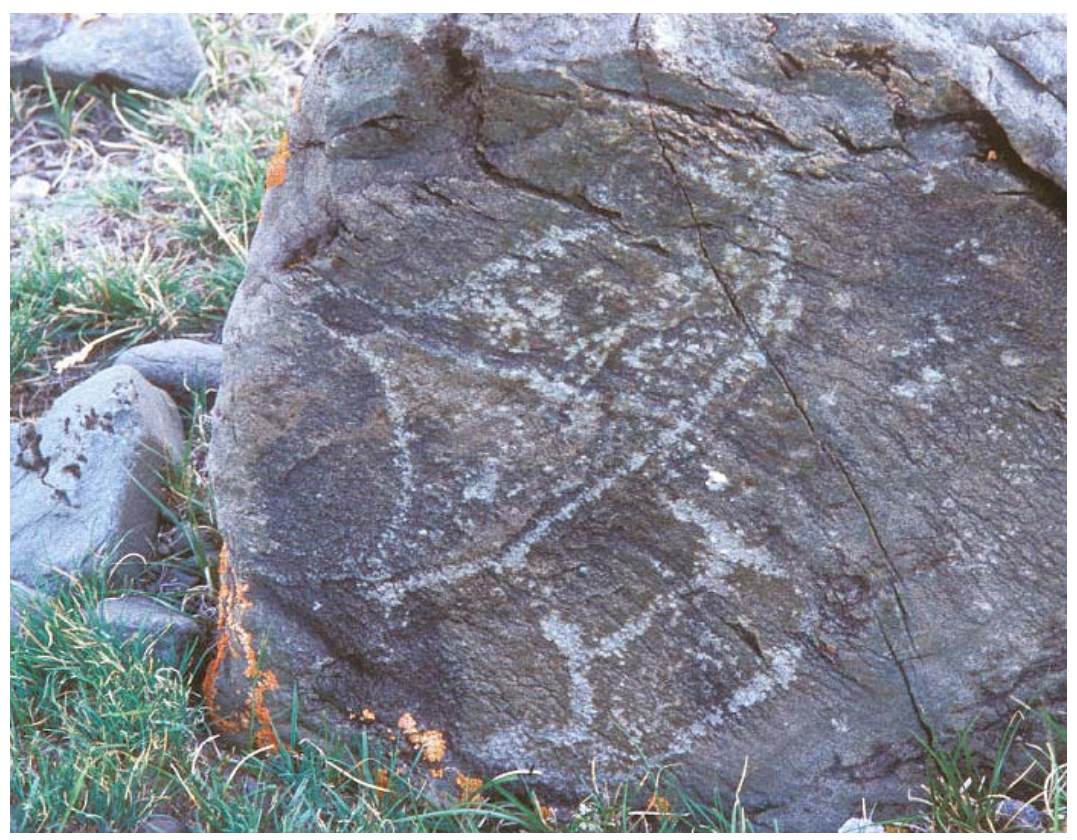


Figure 10. Partially visible image of elk on boulder buried in silt. Early Bronze Age. Tsagaan Salaa III. (http://oregondigital.org/u?/maic,3052).

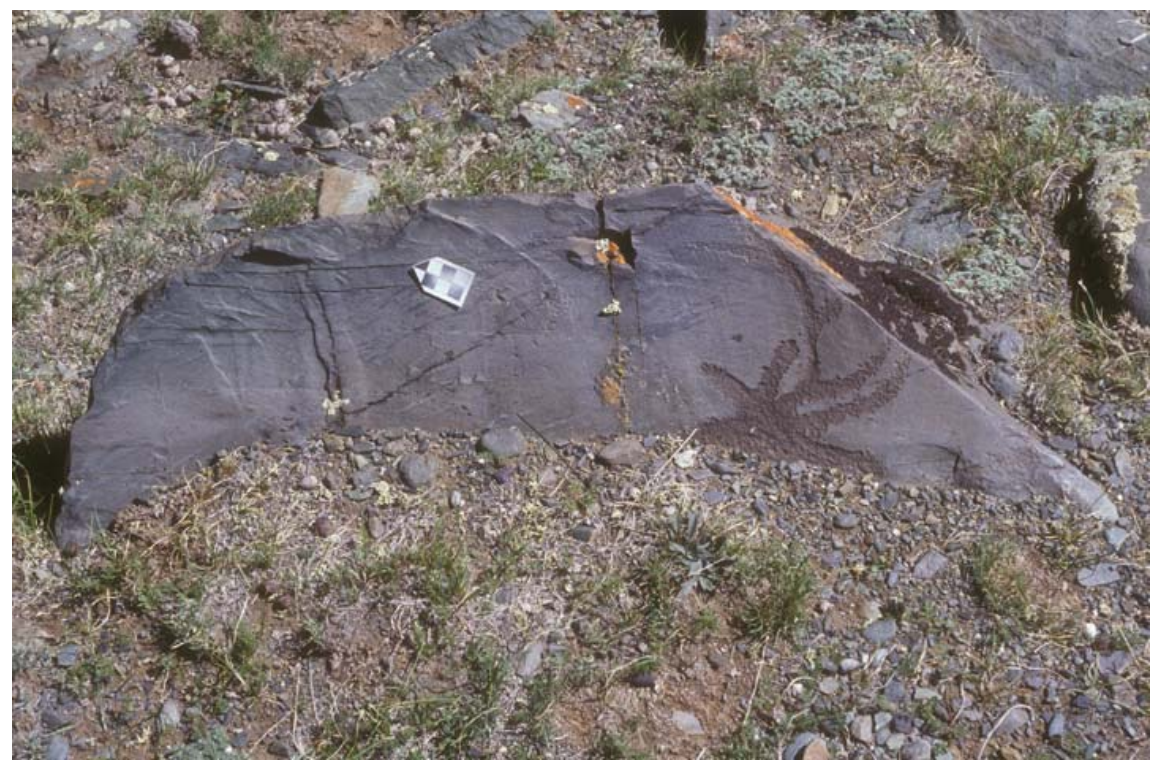

Figure 11. Elk image on uncovered boulder. Early Bronze Age. Tsagaan Salaa III. (http://oregondigital.org/u?/maic,3053).

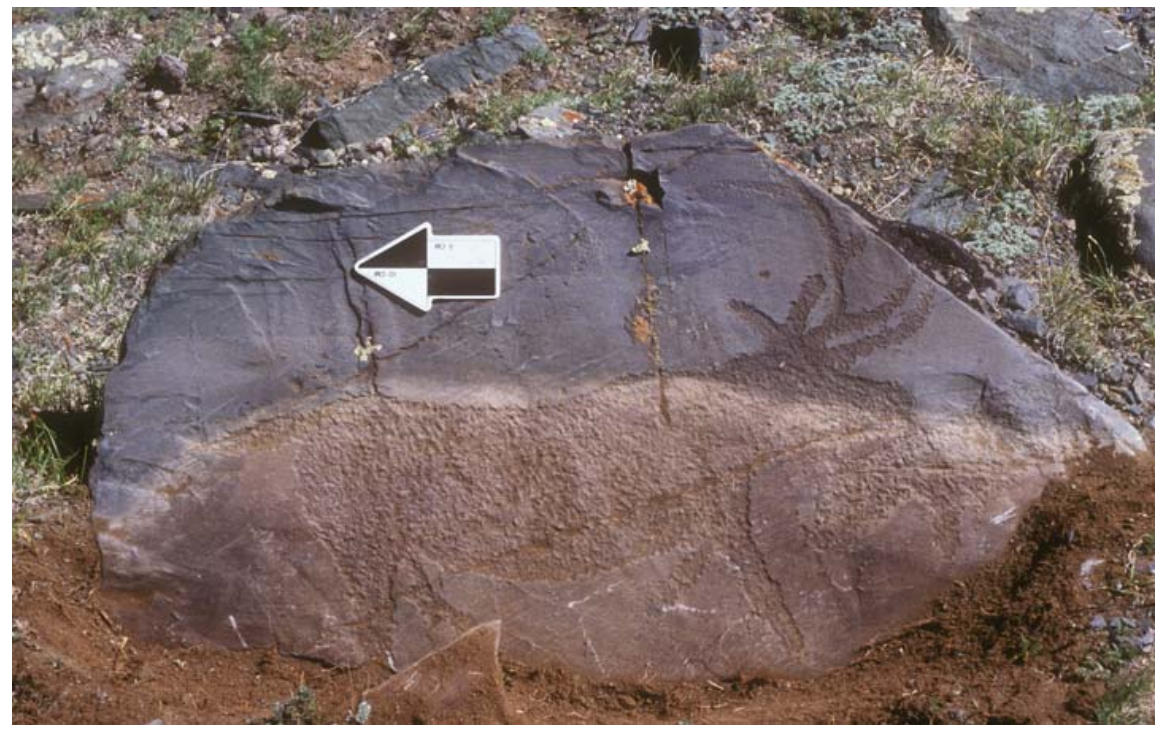

In the end, the most convincing indicators of past environments are offered by the images themselves and the implications they carry regarding habitat. Certain animals may be considered indicator species, their habitats and dietary needs indicating the existence of specific environments. As grazers and browsers, the elk (Cervus elaphus sibiricus) represented repeatedly across the complex of TS-BO require both forest cover and forest-edge habitat. At present there is no such habitat anywhere in this region except to the south around the lakes (nuur) Khoton, Khurgan and Dayan; and to judge from the essentially treeless aspect of the Oigor drainage, there has been no elk habitat for more than two thousand years. Moose (Alces alces) - represented on many surfaces and particularly in the vicinity of the mouth of the Tsagaan Salaa River-require huge amounts of vegetation including forbs, fresh shoots and aquatic plants. The style indicated by the TS-BO moose images and the hunting 
compositions in which they are embedded are clearly indicative of the early to late Bronze Age [19]. At the same time, there are no moose images associated with any Iron Age or Turkic period imagery. Thus we would have to conclude that for a relatively brief period in the second millennium BCE, the habitat of this complex supported the presence of moose. By contrast, it is not surprising that so many images of aurochs (Bos primigenius primigenius) here and elsewhere in the Mongolian Altai are archaic in appearance or that their images seem to disappear from rock art well before the end of the Bronze Age. Horses and aurochs belonged to the Pleistocene megafauna that ranged across the cold steppe and taiga of Eurasia. They would have inhabited northwestern Mongolia before the expansion of the forests that supported elk, but they could have survived, also, into the later period if forest cover did not displace adequate grassland. Significantly, images of aurochs disappear by the mid-Bronze Age, at about the time when wild yak (Poephagus gruniens L.) also disappeared and were replaced by domesticated yak. What combination of elements caused the aurochs (and wild yak) to be lost from the representational pantheon is unclear. It does seem certain, however, that the appearance, survival and disappearance of large animals represented in rock art must be associated with the climate and vegetation history of a region [14,20].

Images of bear (Ursus arctos) are relatively unusual in the TS-BO and Upper Tsagaan Gol complexes, but they do exist; and in every case the style in which the compositions are rendered indicate a date no later than the Bronze Age. The treatment of the horse and bear in Figure 9 strongly suggests a date in the Late Paleolithic period while other images from Upper Tsagaan Gol were certainly executed in the Bronze Age. Bears require the fresh shoots and fruits of a forest environment as well as streams with abundant fish. While fish do still exist within Altai streams, there is only one contemporary environment in northwestern Mongolia where bears still survive-that is, where there exist extensive forest cover and mountain streams. At present, those requirements are met only in the area south of the Great Lakes, Khoton and Khurgan Nuur, although rumors persist that bear can be found in the northern part of Bayan Ölgiy, in the remote Chikachevyn nuuru (range). Bear are still well known, of course, in the heavy forests of the Sayan and Russian Altai Mountains.

Horses have inhabited the Eurasian steppe since deep in the Pleistocene and have been represented by humans since the Late Paleolithic period. Within the Mongolian steppe and mountain-steppe and previous to horse domestication in the Bronze Age, that animal was probably represented by the Tarpan (Equus ferus ferus) or the Mongolian Takhi, also known as Przewalski's horse (Equus ferus przewalskii). Both animals would have required extensive and open grassland. For that reason, a number of images of wild horses found in the TS-BO complex and executed in an archaic technique and style must refer to the period previous to the expansion of forests or after the retreat of that habitat. Two horses from BO II (Figure 12) capture the heavy bodied aspect of the archaic wild horse, as does an almost invisible horse on a low boulder from the southern edge of TS IV (Figure 13) and a horse on a blackened boulder from TS V [21]. The fact that horses continued to appear throughout the Bronze Age together with elk indicate that the contemporaneous environment must have supported both species: that is, forest and forest edge as well as open steppe. 
Figure 12. Two horses, contoured. Pre-Bronze Age (Paleolithic period). Baga Oigor II. (http://oregondigital.org/u?/maic,2809).

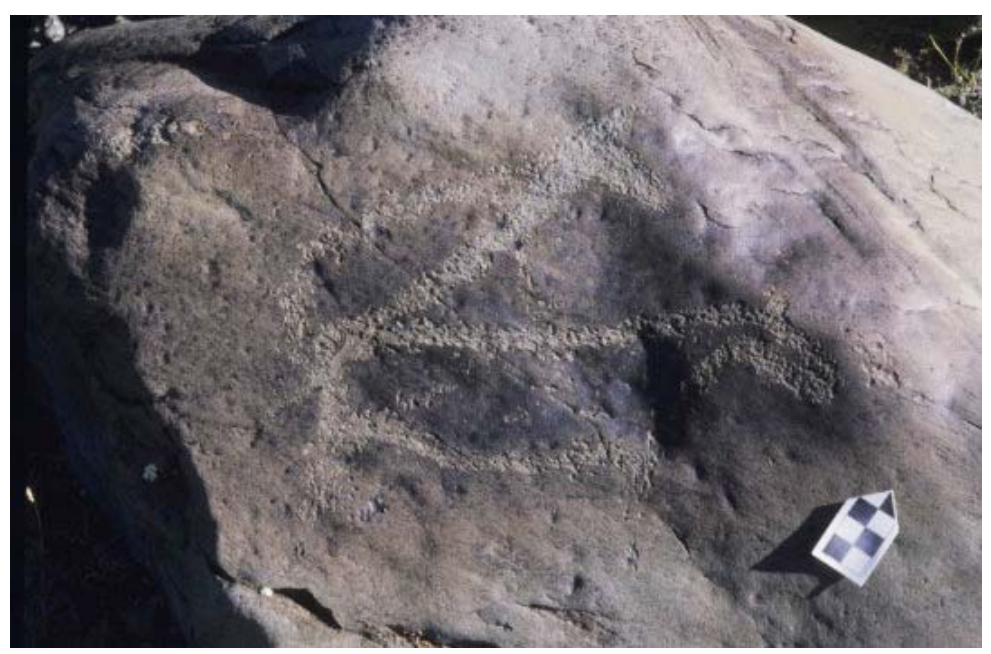

Figure 13. Faint image of a horse on a flat boulder. Pre-Bronze Age. Tsagaan Salaa IV. (http://oregondigital.org/u?/maic,2626).

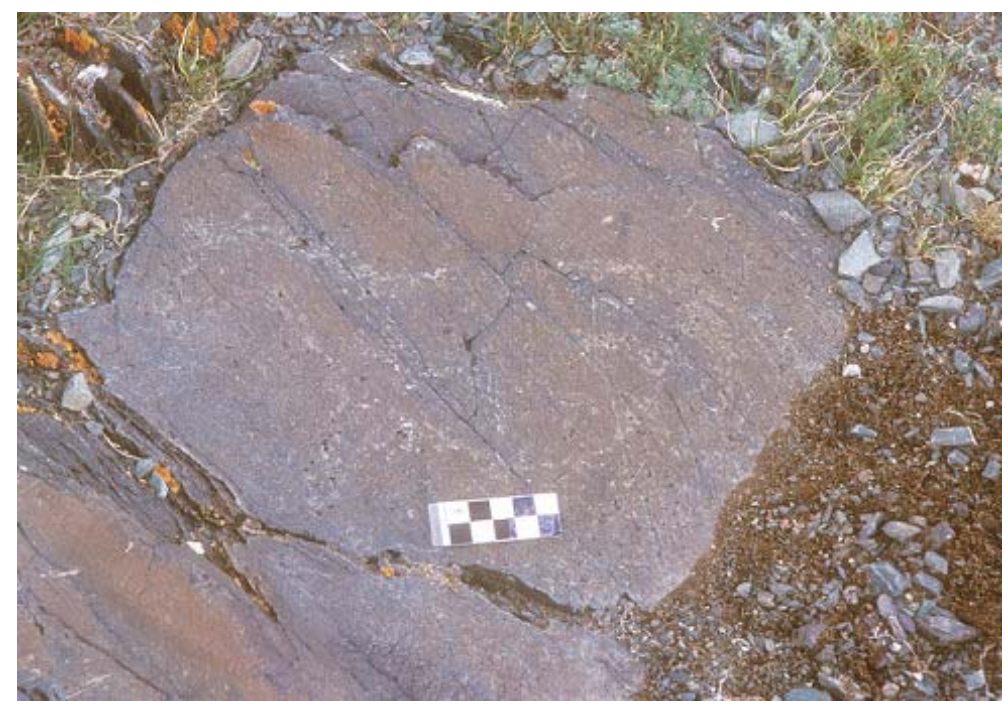

Argali (Ovis ammon ammon) are regularly represented in an archaic style in TS-BO. This is yet another species attested in Pleistocene levels in Russian Altai sites [4,8]. Archaic images of ibex (Capra sibirica) within the TS-BO complex, as well as at Aral Tolgoi (Figure 14), echo the remains of that animal attested in the Okladnikov Cave in the Russian Altai where they are said to have been found on the same strata as mammoths, rhinoceros, horses and elk, inter alia [8]. Both species require rocky highlands and ridges with alpine grazing; neither is at home in a low-level forested environment. The fact that they were represented regularly in Altai rock art only in the Bronze Age may indicate that by that time, hunters were going higher up the slopes in search of game, and that these animals had become more important as a source of meat. 
Figure 14. Ibex and frontal stick figures. Pre-Bronze Age. Aral Tolgoi. (http://oregondigital.org/u?/maic,2093).

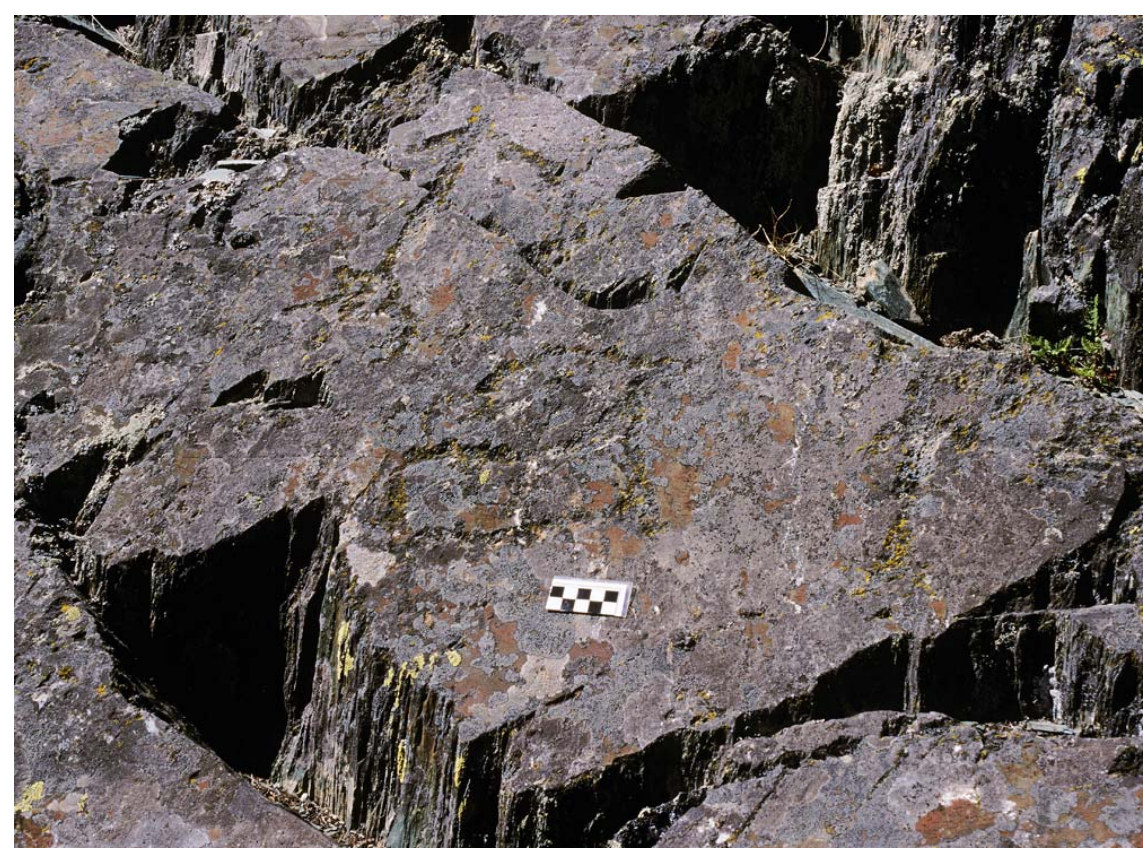

Within the TS-BO complex, there are a few representations of one other significant indicator species. Two, and possibly four, images appear to refer to mammoths (Mammuthus primigenius). These include one located on a small boulder in the lower section of TS IV and executed in an archaic manner and with a clearly articulated trunk (Figure 15).

Figure 15. Mammoth (?) with contoured body and silhouetted head. Paleolithic period. Tsagaan Salaa IV. (http://oregondigital.org/u?/maic,799).

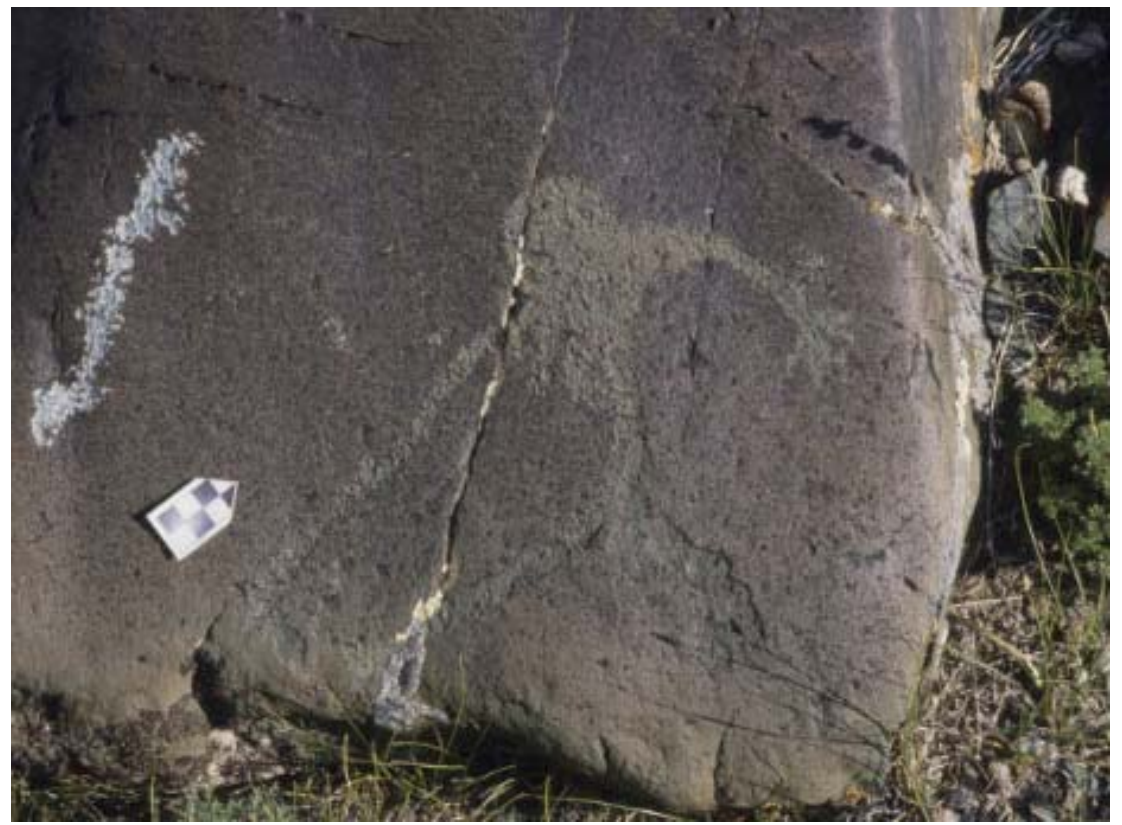


Another, more convincing image from BO III (Figure 16) has unfortunately been marred by modern writing. It may be disappointing that these images have no tusks, but their absence may say more about the technical confidence of the artists than about the "true" nature of the animal. If we accept the identification of these images as mammoths, then we are confronted with representations that can only be of Pleistocene megafauna. Whether because of the increasing humidity of the environment at the end of the Pleistocene or the consequent replacement of xeric vegetation by mesic vegetation or, as some would have it, by hunting pressures [22], mammoths disappeared with the end of the cold steppe [23]. In the few regional sites for which we have faunal data, mammoth bones appear in the earliest strata, together with rhinoceros and elk [24,25]. These images, therefore, indicate an approximate end date (11,500 BP) for their execution.

Figure 16. Mammoth overlaid by contemporary writing. Paleolithic period. Baga Oigor III. (http://oregondigital.org/u?/maic,1107).

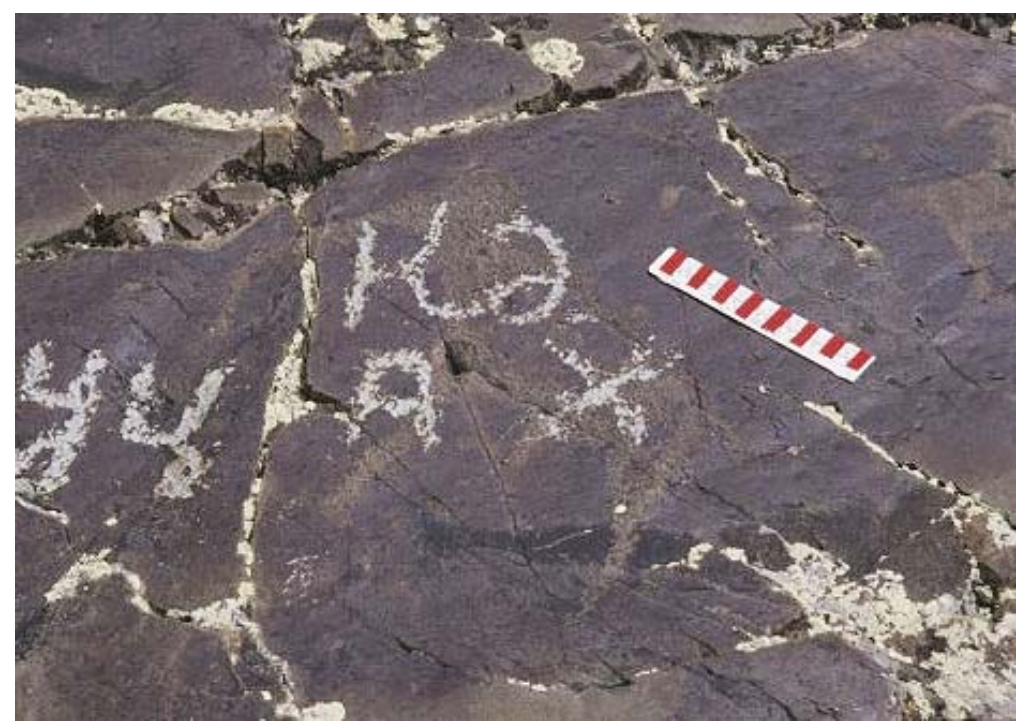

Each animal species frequently represented at TS-BO-mammoths, aurochs, horses, argali, ibex, elk, moose and bear-reflects a variety of paleoenvironments, some of which would have been incompatible in the same region at the same time. On the Mongolian side of the Altai Mountains one must imagine a cold steppe supportive of horses, aurochs, rhinoceros and mammoths. Within that dominant habitat there existed a mosaic of forests supportive of elk and possibly bear, but lacking extensive riparian zones for moose or boar. In other words, the constraints of paleoenvironmental data together with the manner of executing images and their style offer a reliable means for proposing general dating for patently archaic images. What we need, however, is more certain data relating to the paleoenvironment of northwest Mongolia. Fortunately, that exists; and the clearest source for that information virtually adjoins the site known as Aral Tolgoi, the largest and best-preserved concentration of archaic imagery in northern Asia.

\subsection{The Imagery of Aral Tolgoi}

The complex referred to here as Aral Tolgoi takes its name from the hill (Figure 17) lying at the far western end of Khoton Nuur in Bayan Ölgiy aimag, northwestern Mongolia (Map 2). Khoton Nuur- 
Pelican Lake-is one of three large lakes tucked up against the high mountains separating Mongolia from China. The glacial origin of Khoton Nuur and of its twin directly on the east, Khurgan Nuur, is evident in the huge moraines that border the north side of the lakes and in the smaller but deeply crevassed moraines on the east and south ends of Khurgan Nuur. To the west and northwest of Aral Tolgoi rise the ridges of the Russian and Chinese borders. On the south and west, the mountains are covered with forests of larch (Larix sibirica) and pine (Pinus sibiricus); but above the trees, the rocky peaks and ridges are bare of vegetation and reflect the shapes of glaciers that have now largely disappeared. In fact, the forests found in this far corner of Mongolia are the last of more extended stands that covered stretches of mountainous Bayan Ölgiy in the early-middle Holocene. In valleys to the north of the lakes, remnants of those forests can be seen on north-facing slopes, but these, also, are fast disappearing under the pressure of logging and grazing ruminants.

Figure 17. Aral Tolgoi seen from the east.

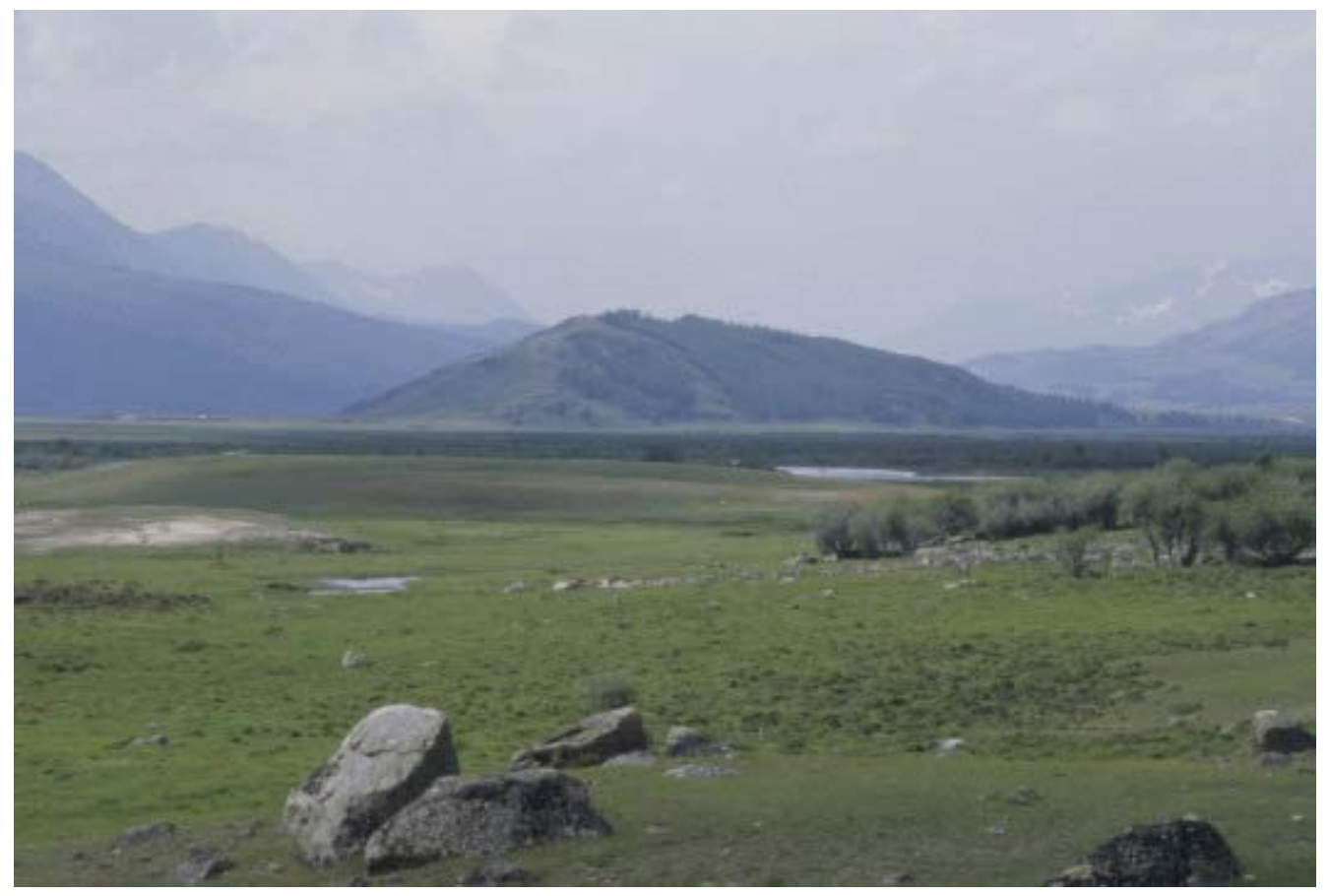

By comparison to the peaks around it, Aral Tolgoi has a low profile, its whale shape lying in the center of a flood plain bordered on the north by the silt-laden waters of the Tsagaan Uss (White Water) and on the south by the clear waters of the Khara Salaagiin Gol. Seen from the east, Aral Tolgoi appears to be a long hill covered with thick larch forest on its northern side and western end (Figure 17). The western half of the ridge is covered by rich grasses on which rest huge boulders left by the glaciers that previously filled this valley. Those same glaciers smoothed the top of Aral Tolgoi and crushed and scraped its rocky outcrops (Figure 18). These are now most visible on the eastern half of the ridge and on the slopes leading from the ridge down to the escarpments on the hill's south side. Given what we know of the paleoenvironment of this valley, we can assume that beneath the thick forests on Aral Tolgoi's north and western slopes might be located other, now lost outcrops. 
Figure 18. Shattered bedrock surface at the top of Aral Tolgoi. View to the east, toward Khoton Nuur.

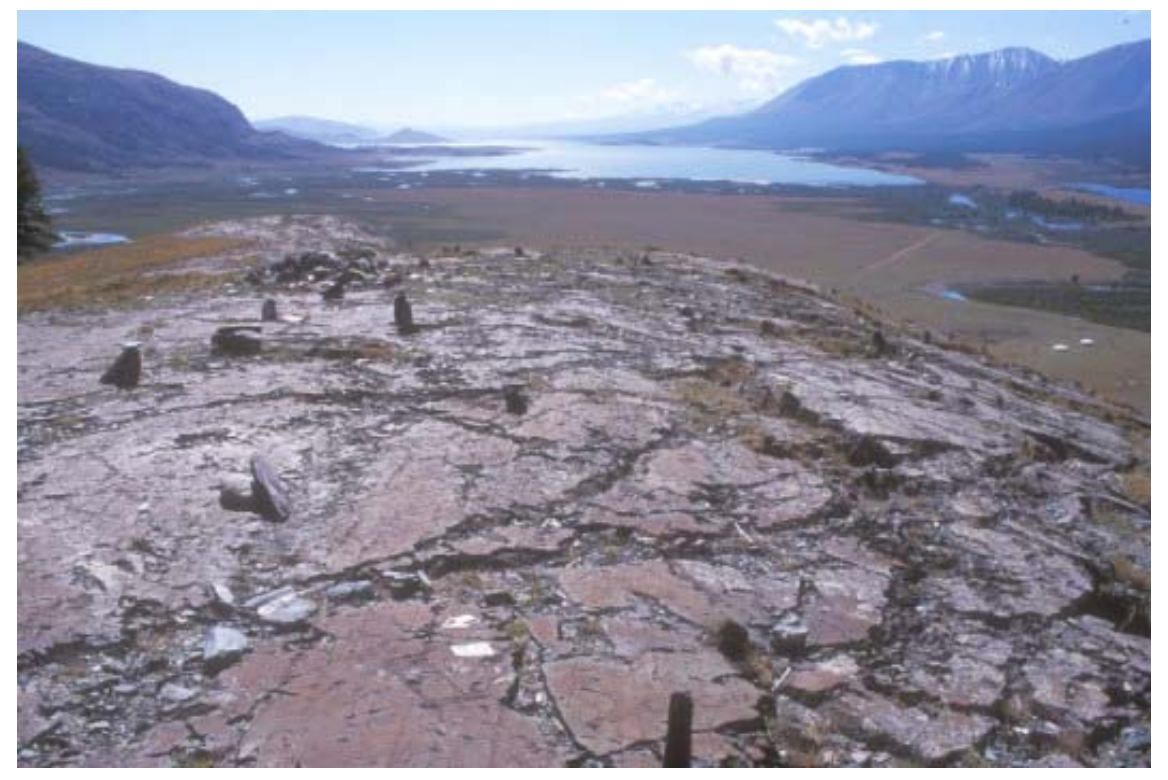

Until we had identified the rock art on Aral Tolgoi (1996), this site was probably unknown to any but the border guards stationed at the eastern base of the hill. Our discovery of this concentration of imagery was fortuitous: we had been looking for another rock art site referred to us by local officials. As we traveled around the north side of Khoton Nuur in search of this site we were engulfed by a ferocious snowstorm that did not abate until we reached the end of the lake. In this manner we missed the intended site (known as Bilüüt). Having gained the west end of the lake and taken note of a variety of surface monuments from the early Iron Age and the Turkic period, we took a few minutes to climb up on Aral Tolgoi to get a better view of the surrounding floodplains. In the slanting rays of the late afternoon sun, we began to pick out shadowy images of animals on the dark and ruined bedrock surfaces. In this manner we became aware of what is probably the largest and best-preserved open-air concentration of rock pecked images from the late Paleolithic-Mesolithic period. Our earlier discussion of the imagery at TS-BO indicates that while the material from Aral Tolgoi is not unique in its age, it does include a number of animal images that are unknown elsewhere in the Altai Mountains except within Khoit Tsenkir Cave (about which more below). More importantly, it is possible to refer the imagery at Aral Tolgoi to the vegetation history indicated in lakebed sediment studies based in Khoton Nuur and reviewed in the last section of this paper.

Aral Tolgoi includes twenty-four decorated outcrops, numbered from southeast to northwest along the hill's ridge [26]. There are, in addition, three large outcrops with pecked images on the hill's northwest side where it drops down to the valley floor. Much of the imagery along the eastern end of the ridge is hardly visible against the blackened and badly damaged surfaces. As one mounts higher on the hill, the imagery is clearer. Aurochs, horses, and elk dominate the pantheon, but one finds, also, occasional argali and ibex. Excluding a few images of Bronze Age hunters and a Turkic rider, there are very few representations of human beings. The most significant composition involving human images (Figure 19) includes a large profile figure holding a club within a group of elk, aurochs and a horse. The style in which the animals are rendered, the appearance (probable) of a hunter, and the 
compositional intentionality suggest a date in the Early or Middle Holocene. A similar or slightly later date may be attached to a grouping in AT_12 including an elk and two frontal figures, one of which appears to be female [27].

Figure 19. Possible hunting scene, with horses, elk, aurochs and a profile human figure. Pre-Bronze Age. Aral Tolgoi. (http://oregondigital.org/u?/maic,2112).

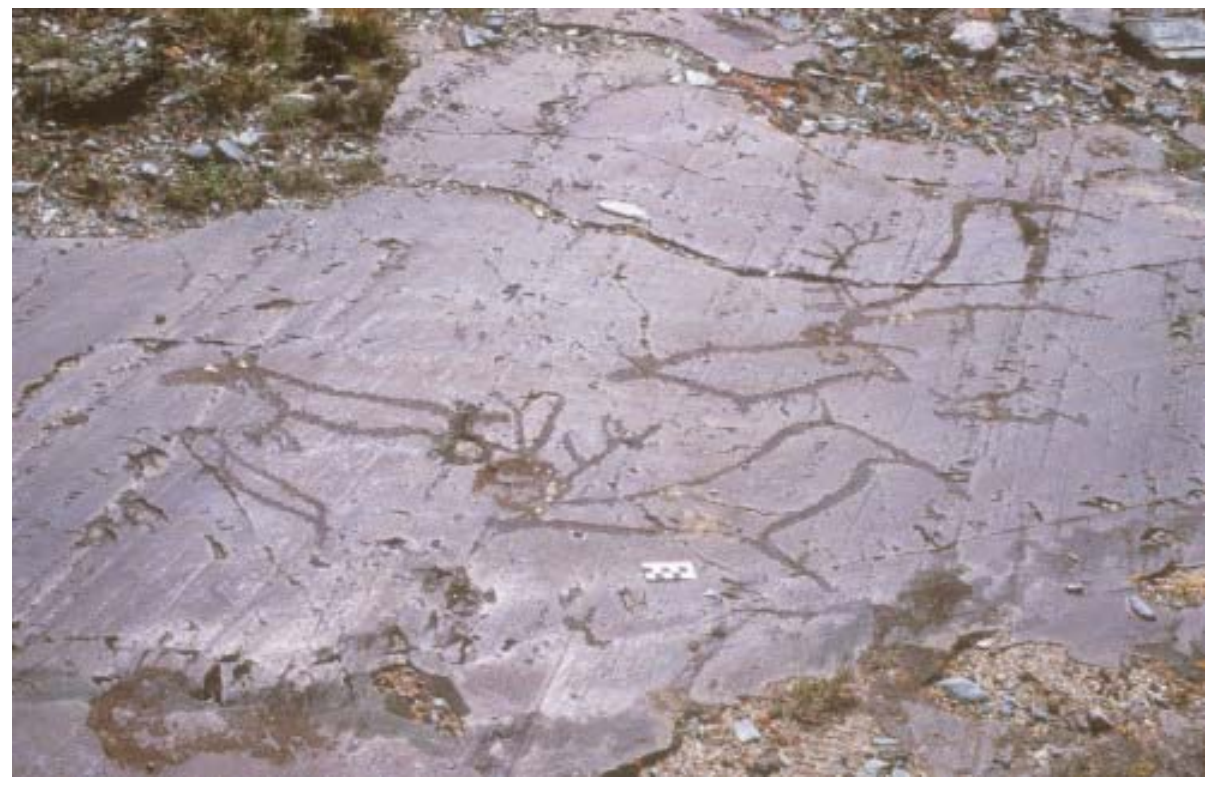

The succession of images along Aral Tolgoi's ridge shifts between those with simple, roughly pecked contours (e.g., Figure 4) and others that may be equally roughly pecked but combine a silhouette with contour technique. While the latter technique may be pre-Bronze Age in date, it is most certainly later in time than the roughly pecked pure contour. In this respect, the composition from AT_16 (Figure 7), mentioned earlier, is particularly intriguing. The crumbling surface is dominated by an elk with large body, elegantly extended neck and head and with archaic, vestigial legs. A silhouetted argali is superimposed on the elk's hip; and below the elk, a partially silhouetted elk covers horse. The appearance of elk images indicates that the contemporary environment must have included some forested habitat; that is, the large elk must refer to a point in the several-thousand year transition spanning the late Pleistocene-early Holocene, when forests were beginning to appear around the lake. At the same time, the primitive style and contoured execution of the large animal in contrast to the superimposed and silhouetted animals suggest at least two layers to this composition-the large elk being earlier and the argali and smaller elk later.

The worn image of a massive horse from AT_13 (Figure 20) and the deeply eroded ibex from the same section (Figure 14) could have been executed as early as the Late Paleolithic period. In the case of the ibex, the apparent reduction of four legs to two inverted cones argues for an archaic date. Further up the ridge and within section AT_21 is a surface that has been weathered more than most and on which it is possible to make out imagery only in the most oblique of lights [28]. Included in this panel are at least two profiled, contoured ibex with heavy bodies and massive horns. Here one can say that the worn character of the surface, the treatment of the animals and the dating of analogous images from European Paleolithic sites argue, also, for a pre-Bronze Age date. A similar conclusion applies 
to the magnificent unfinished aurochs from AT_24 (Figure 4) and to a contoured elk from AT_23 (Figure 21). Although the second animal is now obscured by lichen, its simple contours were clearly executed with direct blows using a heavy instrument. The archaic aspect of both images argues for a date no later than the Mesolithic period and probably earlier.

Figure 20. Horse, worn and covered with lichen. Pre-Bronze Age. Aral Tolgoi. (http://oregondigital.org/u?/maic,2095).

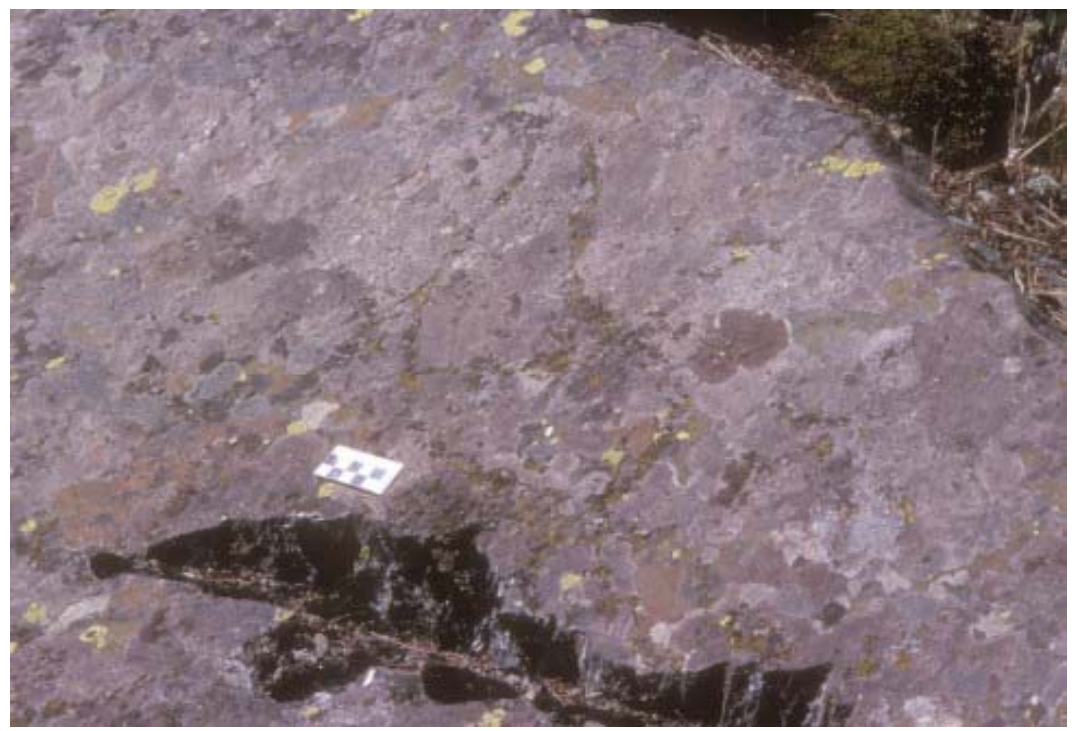

Figure 21. Contoured elk image and an identified element. Pre-Bronze Age. Aral Tolgoi. (http://oregondigital.org/u?/maic,2148).

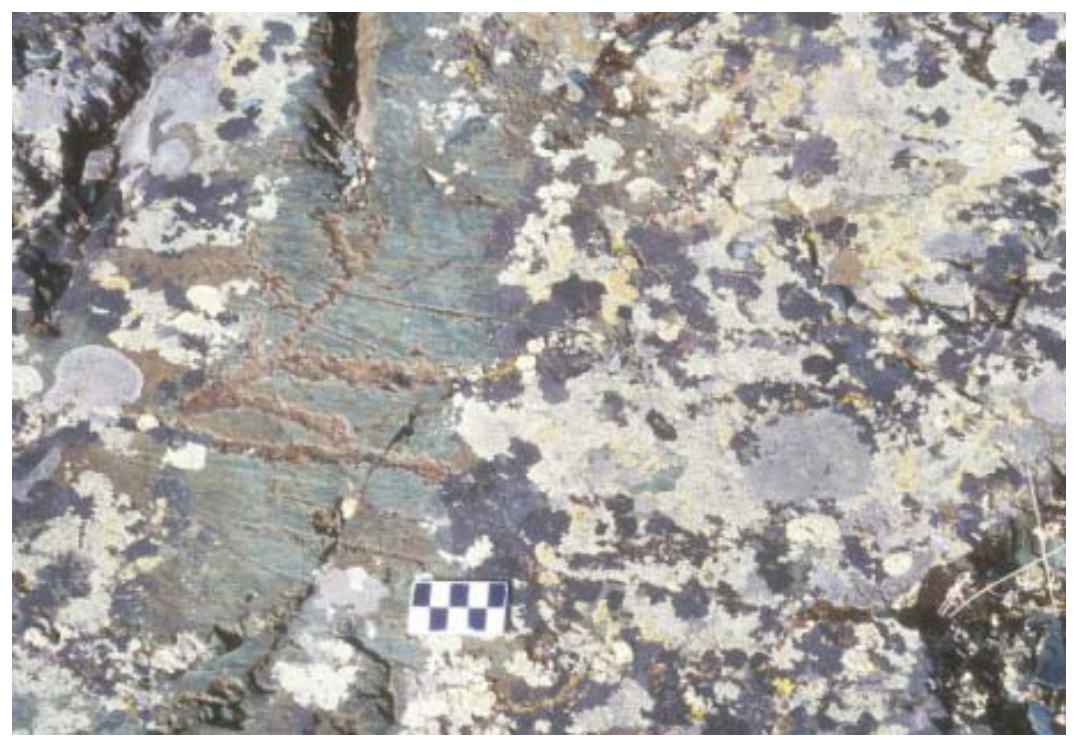

By contrast, a third elk image from the same outcrop bears several stylistic signs of a later date (Figure 22). The animal appears to have been executed with finer, indirect blows, its body is rendered in a partial silhouette, and its long, slender legs are quite different from the inverted cones of the elegant elk from AT_16 (Figure 7). Thus differences in execution and style offer the possibility of distinguishing earlier and later images, particularly when they are juxtaposed on the same surface or, even better, when they are overlaid. An example of overlay that assists in relative dating is offered by a 
fine aurochs from AT_17 (Figure 23) and the smaller animals underlying and overlaying its body. Returning to the magnificent unfinished aurochs from AT_24 (Figure 4), although that roughly contoured image is juxtaposed with the image of an elk [29], the distinctions in style and execution clearly indicate distinctions in time: by contrast to the aurochs, the elk has been carefully and densely pecked out in silhouette fashion, a style indicating the Bronze Age.

Figure 22. Elk partially silhouetted and possibly unfinished. Pre-Bronze Age or Early Bronze Age. Aral Tolgoi. (http://oregondigital.org/u?/maic,2146).

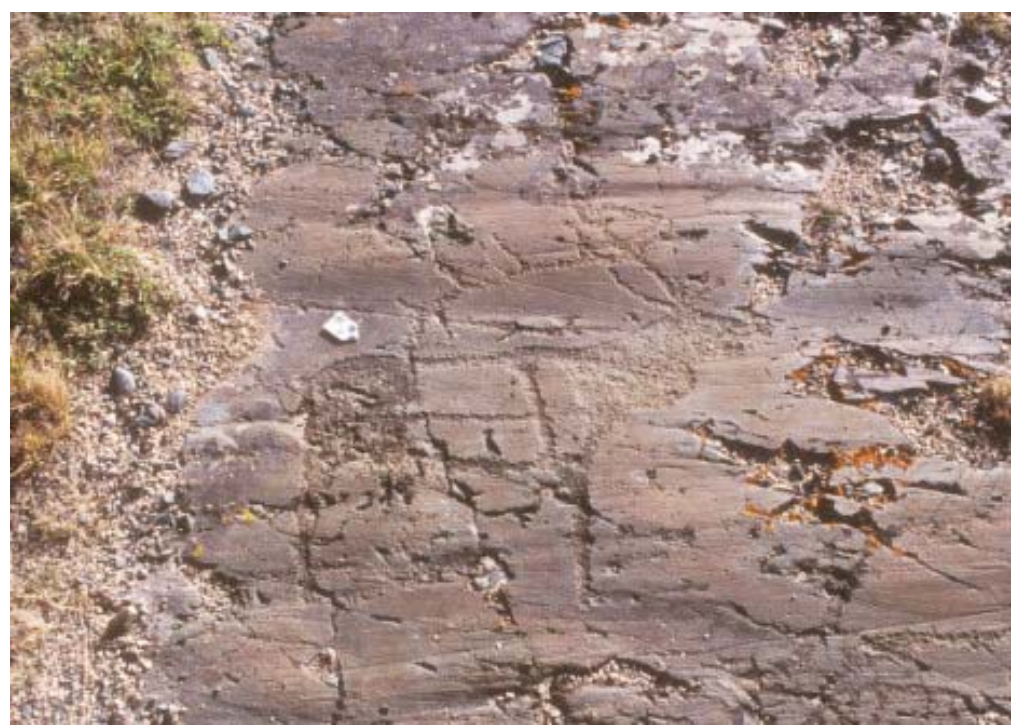

Figure 23. Aurochs superimposed on a small, contoured animal and overlaid by a silhouetted argali. Pre-Bronze Age. Aral Tolgoi. (http://boundless.uoregon.edu/u?/ maic,2111).

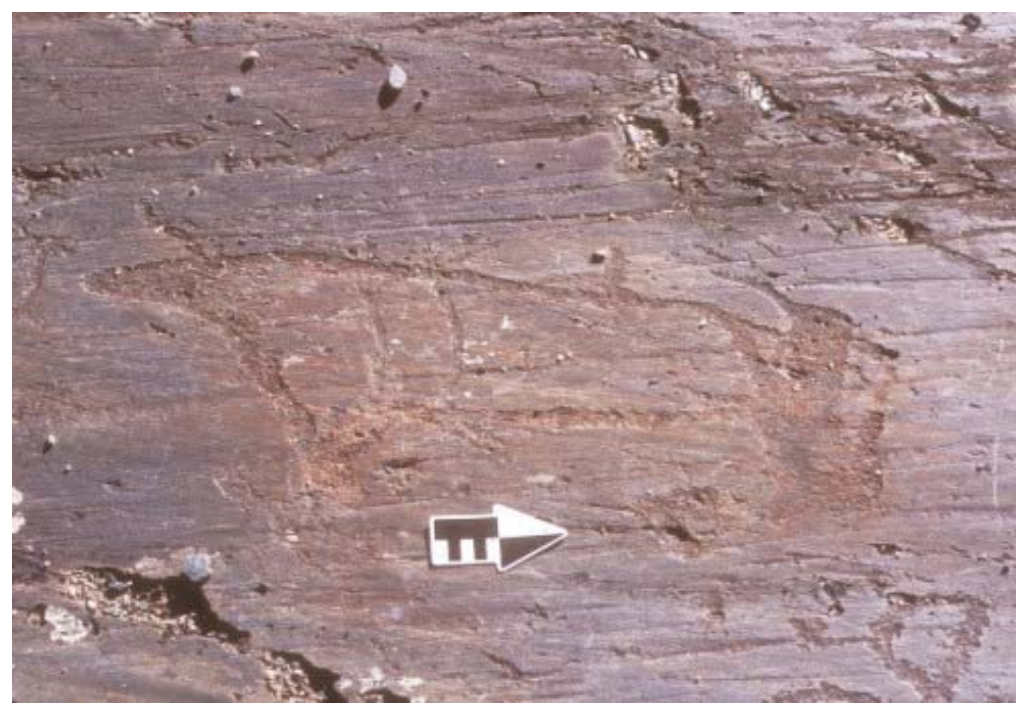

The highest and most richly decorated section on Aral Tolgoi is identified as AT_22. Before the development of the heavy forest on the north side of the hills, the section must have offered unobstructed views down to the east, north and south and distant views to the mountains on the west. The surface now is crumbling (see Figure 18) and a small hut and a marker set up by the Mongolian 
Border Patrol located at the east base of the hill have obliterated several panels. Nonetheless, it is still possible to make out many images of considerable age, including the badly damaged surface with a powerful aurochs juxtaposed with a fat horse, both executed in contour technique (Figure 8). These animals could refer to the faunal reality of the Late Pleistocene or the Early Holocene. On the other hand, the massive treatment of the images and their seemingly random juxtaposition argue for a date in the Paleolithic period. Another image is more striking. On a fragmentary surface has been preserved an animal that could only refer to a rhinoceros (Coelodonta) (Figure 24). Its body is massive, its head small, and its legs take the form of two inverted cones. Its horn may have been lost in the stone break above its head. The animal is defined by a wide, uneven band of deep peck marks that had to have been executed directly with a heavy instrument. Those who would argue that this is a boar (Sus scrofa) rather than a rhinoceros should consult the very different treatment of a boar's body and the length of its head relative to its body: there is, in fact, little in common between the representation of a boar and this animal [30]. We know that rhinoceros disappeared from the Eurasian steppe before the disappearance of the xeric vegetation on which it depended. By contrast, the boar's opportunistic diet of fruits, nuts, roots, grasses and carrion requires an at least partially forested setting, i.e., a date no earlier than the Mid-Holocene.

Figure 24. Rhinoceros. Paleolithic period. Aral Tolgoi. (http://oregondigital.org/u?/ maic,2131).

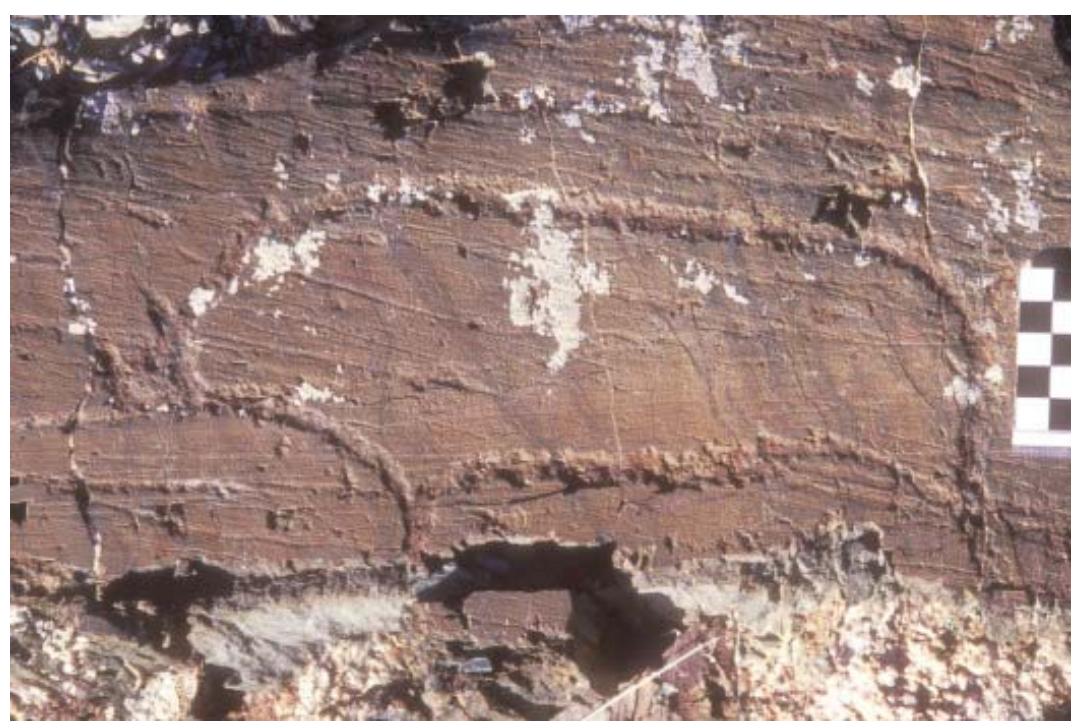

When we first documented AT_22, we recorded four panels with the images of ostrich (Struthio anderssoni); since that time, unfortunately, the most complex of these panels has been destroyed by the implantation of an elevation marker on the top of the hill. One existing panel includes two ostriches partially overlaid by a horse (Figure 25). The contoured and striped treatment of the large birds differs from the partially silhouetted treatment of the horse. The second, now lost panel, included two large contoured birds and two contoured horses (Figure 26). In the center of the grouping is a strange element, possibly a frontal human figure, but that is not at all clear. The single image on another panel is more primitive but clearly shows the large contoured body, long legs and small head of the ostrich [31]. A fourth panel includes a large bird, with ostrich-like body but with a strange round head [32]. 
Figure 25. Two ostriches and a horse. Pre-Bronze Age. Aral Tolgoi. (http://oregondigital.org/u?/maic,2137).

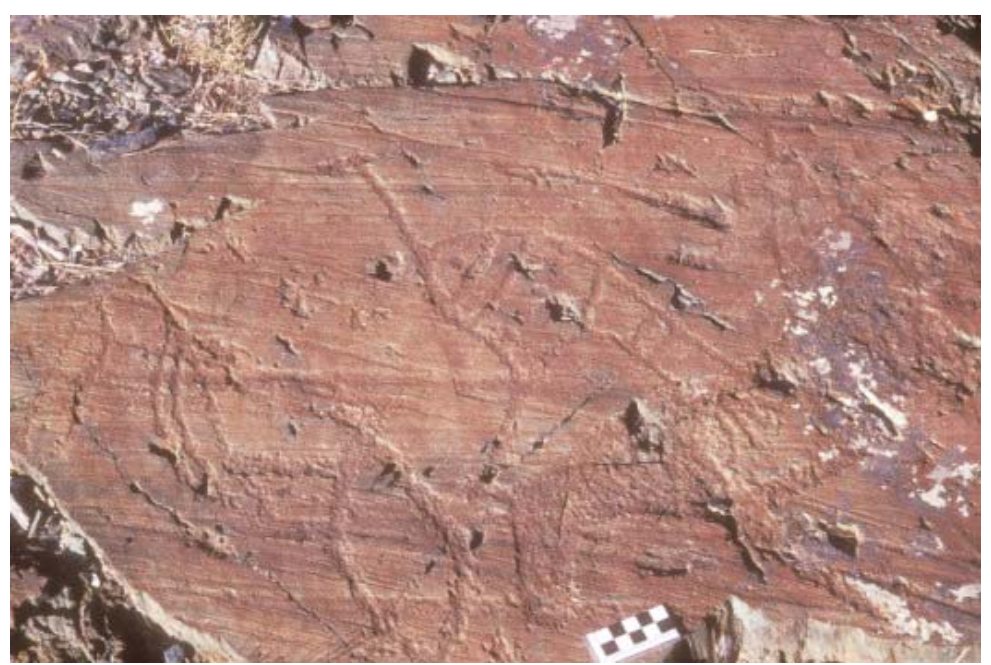

Figure 26. Two ostriches, two horses and an uncertain element. Pre-Bronze Age. Aral Tolgoi. (http://oregondigital.org/u?/maic,2138).

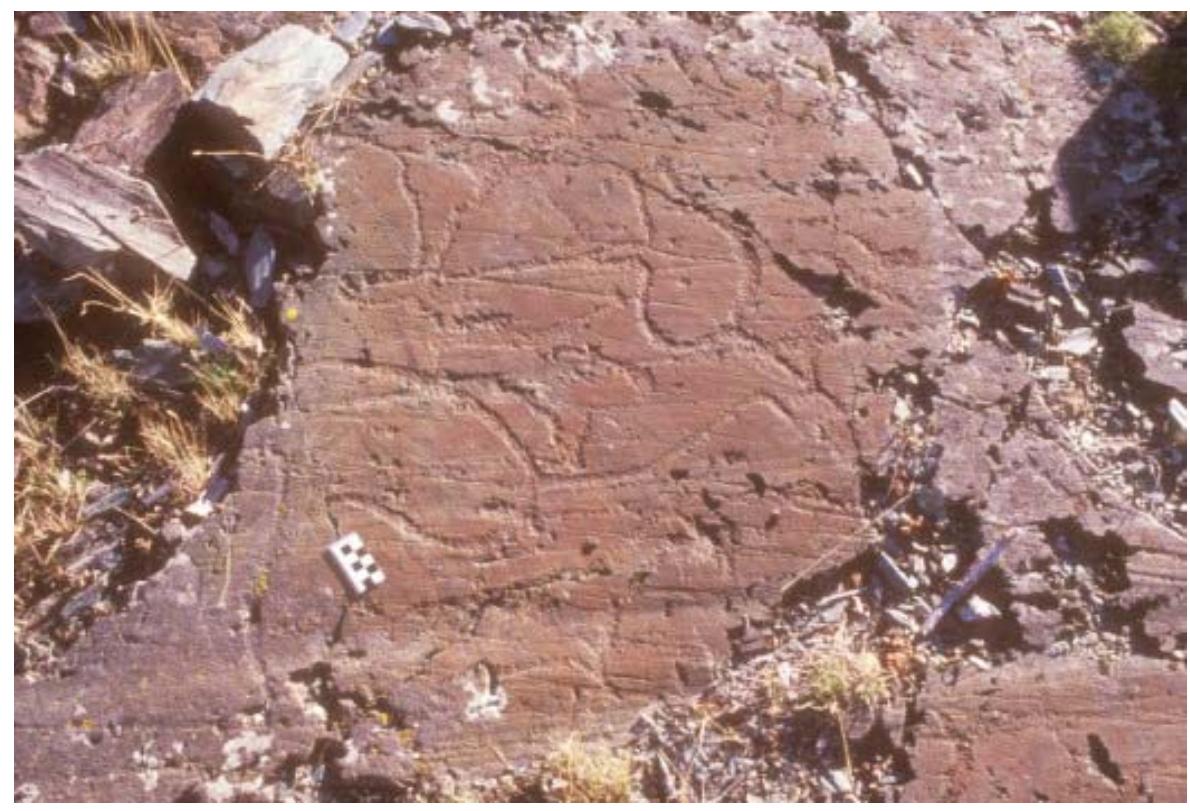

\subsection{Archaic Imagery of the Upper Tsagaan Gol Complex}

The dating of archaic imagery within the complex of the Upper Tsagaan Gol is more problematic. The valley lies just below what were (until recently) heavily glaciated peaks, and the valley floor and the cliffs lining its north and south sides everywhere reveal intense glacial action. The extremely localized concentration of archaic images at three different points in the complex suggests that valley glaciers may have advanced and retreated repeatedly well into the Early Holocene. There are no obviously datable images such as mammoths, rhinoceros or ostrich, but at one of the highest points in the valley (KS_A4) two archaic images of aurochs are suggestive of a very early date. One of these is crudely pecked and unfinished (Figure 27), while the other seems to have been given a pouch in its belly at a later time [33]. In another section (SK_C1) at the top of the valley, the head of an unfinished 
elk was clearly executed with a primitive, direct technique (Figure 28). While this image may be later than the contoured aurochs, its execution and extremely dark patina suggest an early date, certainly no later than the early Holocene. Further down the valley, on the large outcrop of SK_J8, the contoured images of aurochs, a group of elk, aurochs and argali are overlaid in a random fashion indicative of a complete lack of interest in psychological interaction; their archaic style and the combination of fauna also suggest a Paleolithic or Mesolithic date [34]. Finally, at the lowest part of the complex and at the top of a low hill on the south side of the valley, are a number of images executed in both contour and silhouette techniques (Figure 29); these, also, must date to a period before there was any interest in the kind of compositional articulation one finds in the Bronze Age. In all these cases, certainty regarding date would require a much more finely tuned understanding of the valley's pattern of glacial advance and retreat in the late Pleistocene and of the gradual intrusion of coniferous forest. However, given the information available from sites in the Sayan Mountains [6] and in the adjoining Russian Altai [4,8], the images here of aurochs, elk, argali and ibex may point to execution in the late Paleolithic period.

Figure 27. Aurochs, unfinished. Pre-Bronze Age. Upper Tsagaan Gol. (http://oregondigital.org/u?/maic,1549).

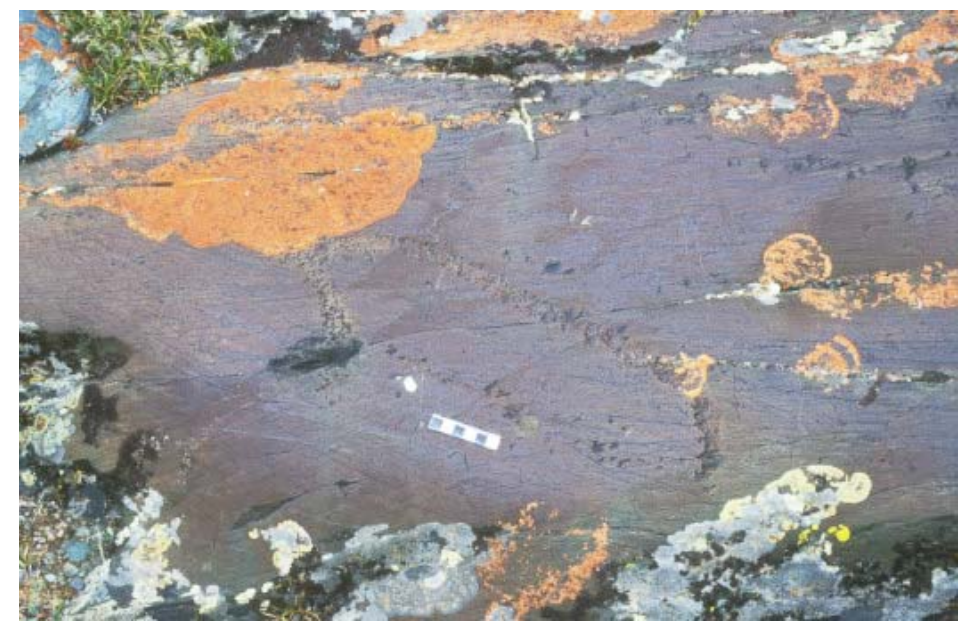

Figure 28. Head of an unfinished elk. Pre-Bronze Age. Upper Tsagaan Gol. (http://oregondigital.org/u?/maic,1874).

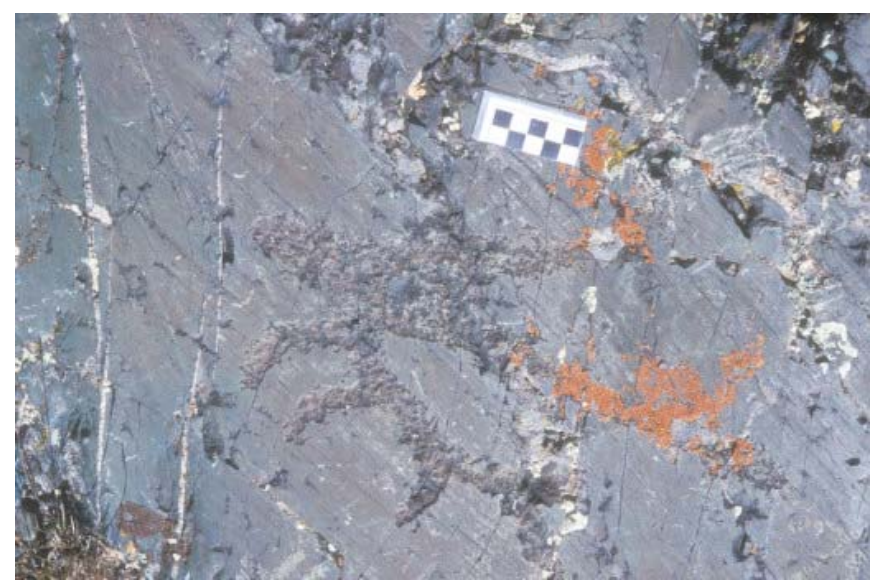


Figure 29. Broken image of an argali or ibex. Pre-Bronze Age. Upper Tsagaan Gol. (http://oregondigital.org/u?/maic,2429).

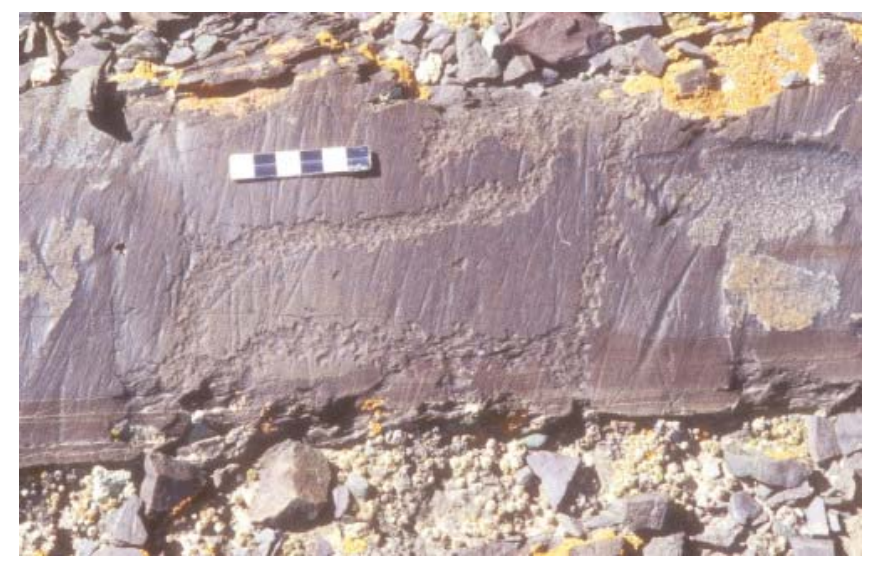

\subsection{Paleoenvironmental Indicators and Their Relationship to Faunal Species}

Analyses of lakebed sediments in both the Russian and Mongolian Altai have supported the reconstruction of the ancient environment of this region as it changed from the end of the LGM to the onset of the late Holocene (c. $4.5 \mathrm{cal}$ yr ka BP). The research site most relevant to the dating of the complexes discussed here and, most particularly, to Aral Tolgoi, is located at the east end of Khoton Nuur. According to the scientists' analysis of the pollen record from that site $[20,35,36]$, before $11.5 \mathrm{cal}$ yr ka BP. the region extending from there to the north, was characterized by cold steppe covered with xeric vegetation (Artemisia, Chenopodiaceae, Betula nana). With the gradual amelioration of climate between that date and 9.5 cal ka BP, spruce (Picea) dominated forests slowly expanded to create a closed tree cover, and mesic vegetation gradually replaced xeric assemblages. This trend continued until approximately 5 cal yr ka BP, by which time a decrease in moisture and lowered lake levels and temperatures resulted in the gradual replacement of spruce by larch (Larix) and pine (Pinus sibirica), the general retreat of forests and the expansion of dry steppe. By 3,000 years $\mathrm{BP}$, northwestern Mongolia had returned to a steppe environment in which the only extensive forests, limited to a narrow band along the Chinese border, are dominated by larch. Other studies have established corroborating evidence for the larger region of Siberia [37,38], northern China [14,39] and northern Kazakhstan [40]. At this point there exists a detailed understanding of the fluctuation of climate, lake levels, and flora over a large region, including that of the Altai Uplift, over a period of more than 16,000 years.

While there have been extensive studies of the cultural implications of climate and faunal-human interactions within the larger region of North Asia, virtually no studies have been undertaken in the Mongolian Altai. Whether scientific excavations in these high valleys would reveal useful faunal remains is unlikely or, at the least, unknown. There are, by contrast, a number of studies of habitation sites in adjoining regions that offer relevant comparisons. As has been mentioned, caves within the Russian Altai indicate the human exploitation of woolly rhinoceros (Rhinoceros tichorhinus), horses, argali and yak during the Sartan period glaciation. Other studies have indicated within the upper Yenisei region the existence of megafauna such as aurochs, woolly mammoths, and rhinoceros down to the end of the Pleistocene, as well as the existence of reindeer (Rangifer tarandus), argali and steppe 
bison (Bison priscus). In the immediate post-LGM, the sites revealed the exploitation of moose, aurochs and wild horse [6]. To the south, at the site of Xiaonanhai in the lower Yellow river basin, rhinoceros and elk (Cervus canadensis), inter alia, have been attested in the period succeeding LGM [41].

Scanty as this information is, combining it with studies of climate, vegetation and fauna for the larger Eurasian region allows one to bracket faunal possibilities in the Mongolian Altai. Whether the petroglyphic images discussed above refer to species valued for practical purposes or to species that enjoyed a cultural value other than that of game is unknown and possibly unknowable. It would seem certain, however, that the archaic images we find in Mongolian complexes refer to species contemporary with the artists who executed them and not to "cultural memories." With this understanding, we can propose the following guidelines. During the Late Pleistocene, northwestern Mongolia was part of the "Mammoth Steppe" that covered the northern reaches of Eurasia [23,42]. While generally characterized by a dry and cold expanse of xeric vegetation, it was dominated by large grazers - that is, megafauna such as mammoths, woolly rhinoceros, horses and aurochs, as well as ostrich. One must imagine, however, that by the late Pleistocene that steppe environment was increasingly broken by a mosaic of boreal forest and mesic vegetation [43].

Woolly mammoths and woolly rhinoceros are thought of as archetypal animals of the middle-late Pleistocene. The southern limit for both species goes directly through the region of present-day Bayan Ölgiy aimag [42]. Rhinoceros appear to have disappeared from Eurasia by 12,000 yr BP, while mammoths lived on into the early Holocene in areas of the far north where steppe habitat survived until as late as 8000 yr BP [42,44]. Within the larger Eurasian steppe zone, the survival of megafauna was thwarted by the expansion of mesic vegetation, coniferous forests, and a soil base unable to support the weight of the large animals. The most archaic images of elk from our Mongolian sites (e.g., Figure 7) suggest an emerging mosaic of open grassland and protective forest edge in the late Pleistocene. The fact that there are no clearly identifiable images of moose at Aral Tolgoi argues that when this far valley was inhabited, vegetation was dominated by the harsh species on which megafauna depended rather than by the browse required for moose. (With that in mind, it is striking to note the distribution of moose imagery within the complex of TS-BO-around what must have been riparian thickets along the Tsagaan Salaa and particularly where it joined the valley of Baga Oigor [45]).

In northern Mongolia, ostrich — which in North Asia required an arid steppe environment—may have lasted until 8.9 cal yr ka BP [46,47]. The ostriches at Aral Tolgoi indicate the previous existence in that region of dry grassland and xeric vegetation, while the rhinoceros image-like the mammoths from TS/BO - indicates a contemporary cold steppe environment. The work of several scholars on the survival of ostrich within Mongolia [46] indicates that Struthio had disappeared by 8,900 years BP. By that time, coniferous forests and mesic vegetation would have replaced the arid steppe environment on which ostrich depended. Thus the images of Coelodonta and Struthio establish an early phase for rock art at Aral Tolgoi with a beginning within the Late Pleistocene (Late Paleolithic) and before 12,000 years BP and termination within the Early Holocene (Early Mesolithic). Presumably many of the archaic images of aurochs, horses and possibly ibex can also be dated within that span of time. By extension, we can confidently assert a similarly bracketed early stage for the mammoth images and for the most archaic images of aurochs and horses at TS-BO. It is probable that to that period, also, date 
the most archaic images of other typically Pleistocene animals such as aurochs and horses. When ibex and argali would have appeared within the paleoenvironment and the pictorial record is not clear, although (as noted above) both species are attested in Pleistocene layers from Okladnikov and Ust' Kan caves in the Russian Altai [24,48]. To judge from the imagery of those species at Aral Tolgoi-where some representations have all the archaic aspect of the oldest horses and aurochs-they may also be markers of the late Pleistocene or of the Pleistocene-Holocene transition.

\section{Conclusion}

The examination of archaic imagery found in three major complexes in the Mongolian Altai leads us to a principle for proposing chronology for archaic images within North Asia. This principle might be rendered formulaically as follows: image (i.e., animal species qualified by the means of execution + style) qualified by known paleoenvironments indicates the general period of execution. This principle can be deployed in the examination of other representations within Mongolia that have been called "Paleolithic" in date. In 1972, the Soviet archaeologist A. P. Okladnikov published drawings of the painted imagery from within Khoit Tsenkir cave in Khovd aimag [49]. This site lies within the Altai Mountains southwest of our study area in Bayan Ölgiy aimag. According to the archaeologist's report, the cave paintings included recognizable caprids, antelopes, horses, ostriches, rhinoceros and a mammoth, as well as many undecipherable marks and images of uncertain identity. Since that time it has been accepted as a given that the cave includes the earliest paintings in Eurasia. That may well be correct, but at this point it is impossible to confirm such an assertion. The paintings have been essentially destroyed through a variety of pressures: the presence of animals in the cave for thousands of years, ambient dust and dirt, the attentions of amateur rock art lovers and, unfortunately, the fact that Okladnikov's team repainted the images in order to see them more clearly.

Other images have long been known from other sites. E. A. Novgorodova published a number of images that appear to be of considerable age: a group of horses and aurochs from the site of Chandman Mountain, in Uvs aimag [50]. These she dates to the Neolithic. She identifies three images from the site of Rashan Khad, in Khentii aimag, as rhinoceros [51]. The images from both sites have also been badly mishandled, and the published drawings are useless for attempting to come to a certain identity and date. However, more recent and excellent photographs of the surfaces at Rashan Khad by a Korean team of archaeologists indicate the deeply pecked contours of heavy bodied animals that are clearly treated with four legs [52]. Considering that detail, it is more likely these animals are bulls executed in the early Bronze Age rather than Paleolithic rhinoceros.

It is possible, even probable, that there are other sites within the Mongolian Altai that include images as early as the Paleolithic period; however, other than the site of Ishgen Tolgoi in Mankhan sum, Khovd aimag [53], they are still not identified or recorded. Within the Russian Altai there is only one known petroglyphic site that has been identified as Paleolithic in date. This is the small concentration of images on the Kalgut River on the Ukok Plateau [54]. This site is located on the western side of the Tavan Bogd ridge, on the other side of which the land drops down into the main valleys of Baga Oigor and Tsagaan Gol. On the grey outcrops of this site over the Kalgut River are a few images of aurochs and horses and several elements identified as partial images. Executed in contours and lacking any compositional context, some of the images do appear very old. The 
most impressive include a faintly pecked elk, an aurochs and three horses on separate surfaces (e.g., Figure 30). All the archaic Kalgut images are executed with the specific characteristics described here as indicative of a Paleolithic-Mesolithic tradition: rough pecked contours, large profile bodies, vestigial legs and the representation of the animals in psychological isolation. A few other large elements identified by the researchers as partial images [55] are actually mineral anomalies in the stone surface. Despite these "false positives," it is clear that the representations at Kalgut belong to the same cultural impulse and layer evident in the Mongolian Altai complexes of Tsagaan Salaa-Baga Oigor, Upper Tsagaan Gol, Aral Tolgoi and, possibly, Ishgen Tolgoi.

Figure 30. Horse. Pre-Bronze Age. Kalgut River, Ukok Plateau. Photo: E. Jacobson-Tepfer.

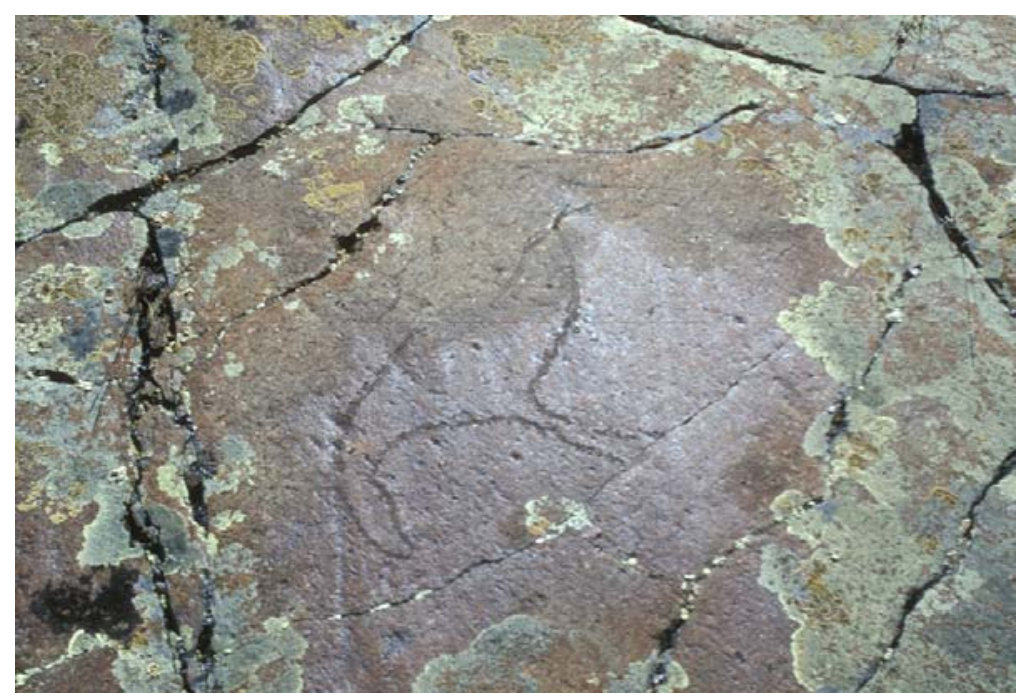

The images from the sites discussed here indicate that within the high Altai and over a several thousand-year period spanning the Late Pleistocene and Early Holocene there existed a rich tradition of visual representation. Altogether, this material constitutes the largest and most undamaged concentration of archaic, open-air imagery in Eurasia. The images of rhinoceros and mammoths push the possible beginning date for that activity back to a period just after the Last Glacial Maximum but before the disappearance of the cold steppe environment. The images of ostrich at Aral Tolgoi confirm the absolute end date of the arid environment on which the giant birds depended. The archaic images of horses, aurochs, elk and argali recreate the vegetation landscape of the late Pleistocene-early Holocene in this region of northwestern Mongolia, indicating a complex mosaic of forest steppe and rocky ridges. The images offer significant information regarding the faunal and vegetation history of that region, while the styles in which they are rendered offer a glimpse into human culture from a period about which we still have little or no excavation evidence. In the powerful representations of animals rendered as if in isolation from each other and with the simplest of techniques, we see the roots of that studied realism and that concern for animal vitality that so marked the succeeding history of Altai rock art from its great flourishing in the Bronze Age through its conventional elegance in the Turkic period. 


\section{Acknowledgments}

The materials on which this discussion is based were gathered by the author within the context of two projects in the Mongolian Altai. The first, the Mongolian-American-Russian Project, Altay (1994-2004), involved a number of colleagues including the author, Damdinsurenjiin Tseveendorj (presently Director of the Institute of Archaeology, Mongolian Academy of Sciences, Ulaanbaatar, Mongolia) and the late Vladimir Kubarev (Institute of Archaeology and Ethnography, Russian Academy of Sciences, Novosibirsk, Russia). The second project, the Mongolian Altai Inventory Project (2004-2010) included, in addition to the author, James Meacham (Director, InfoGraphics Lab, Department of Geography, University of Oregon, Eugene, OR., USA) and Gary Tepfer, photographer. Our search for relevant materials in the field was aided by several individuals including Ayatkhan Atai, presently Director of the Altai Tavan Bogd Protected Area, and Dagys Atai. The arguments presented here, the conclusions and any errors of interpretation are entirely the responsibility of the author.

\section{Conflicts of Interest}

The author declares no conflict of interest.

\section{References}

1. Tseveendorj, D.; Kubarev, V.D.; Yakobson (Jacobson), E. Aral Tolgoin Khadny Zurag (The Petroglyphic Complex of Aral Tolgoi); Mongolian Academy of Sciences: Ulaanbaatar, Mongolia, 2005.

2. Jacobson-Tepfer, E.; Kubarev, V.D.; Tseveendorj, D. Mongolie du Nord-Ouest: Haut Tsagaan Gol. Répertoire des Pétroglyphes d'Asie centrale; Fascicule No. 7. 2 Vols. De Boccard: Paris, France, 2006.

3. Jacobson, E.; Kubarev, V.D.; Tseevendorj, D. Mongolie du Nord-Ouest: Tsagaan Salaa/Baga Oigor. Répertoire des Pétroglyphes d'Asie centrale; Fascicule No. 6. 2 Vols. De Boccard: Paris, France, 2001.

4. Tseitlin, S.M. Geologiia Paleolita severnoi Azii (Geology of the Paleolithic Period in Northern Asia); Nauka: Moscow, Russia, 1979.

5. Michael, H.N. Absolute chronologies of late Pleistocene and early Holocene cultures of Northeastern Asia. Arct. Anthropol. 1984, 21, 1-68.

6. Vasil'ev, S.A.; Semenov, V.A. Prehistory of the upper Yenisei Area (Southern Siberia). J. World Prehist. 1993, 7, 213-242.

7. Janz, L. Chronology of Post-Glacial Settlement in the Gobi Desert and the Neolithization of Arid Mongolia and China. Ph.D. Dissertation, University of Arizona, Tuscon, AZ, USA, Oct. 10, 2011.

8. The Paleolithic of Siberia; Derev'anko, A.P., Shimkin, D.B., Powers, W.R., Eds.; Institute of Archaeology and Ethnography: Novosibirsk, Russia; University of Illinois: Urbana and Chicago, IL, USA, 1998.

9. Dorn, R.I. Chronometric Techniques: Engravings. In Handbook of Rock Art Research; Whitley, D.S., Ed.; Altamira Press: New York, NY, USA, 2001. 
10. Dorn, R.I. Rock varnish. Am. Sci. 1991, 79, 542-553.

11. MAIIC *. Available online: http://boundless.uoregon.edu/u?/maic,1496 (accessed on 9 July 2013).

12. MAIIC. Available online: http://oregondigital.org/u?/maic,2512 (accessed on 9 July 2013).

13. MAIIC. Available online: http://oregondigital.org/u?/maic,1724 (accessed on 9 July 2013).

14. Herzschuh, U. Palaeo-moisture evolution in monsoonal Central Asia during the last 50,000 years. Quat. Sci. Rev. 2006, 25, 163-178.

15. Serebryanny, L.R. Mountain Glaciation in the USSR in the Late Pleistocene and Holocene. In Late Quaternary Environments of the Soviet Union; Velichko, A., Ed.; University of Minnesota Press: Minneapolis, MN, USA, 1984; pp. 45-54.

16. Arkhipov, S.A. Stratigraphy and paleogeography of the sartan glaciation in West Siberia. Quat. Int. 1998, 45, 29-42.

17. Jacobson, E. Petroglyphs and natural history: Sources for the reconstruction of the ecology of culture. Archaeol. Ethnol. Anthropol. Eurasia 2000, 1, 57-65.

18. MAIIC. Available online: http://boundless.uoregon.edu/u?/maic,764 (accessed on 9 July 2013).

19. MAIIC : Gallery Search: moose.

20. Gunin, P.D.; Vostokova, E.A.; Dorofeyuk, N.I.; Tarasev, P.E.; Black, C.C. Vegetation Dynamics of Mongolia; Kluwer Academic Publishers: Dordrecht, The Netherlands, Boston, MA, USA, London, UK, 1999.

21. MAIIC. Available online: http://oregondigital.org/u?/maic,937 (accessed on 9 July 2013).

22. Olivier, R.C.D. Ecology and Behavior of Living Elephants: Bases for Assumptions Concerning the Extinct Woolly Mammoths. In Paleoecology of Beringia; Hopkins, D.M., Mathews, J.V., Schweger, C.E., Young, S.B., Eds.; Academic Press: New York, NY, USA, London, UK, 1982; pp. 291-305.

23. Guthrie, R.D. Mammoths of the Mammoth Steppe as Paleoenvironmental Indicators. In Paleoecology of Beringia; Hopkins, D.M., Mathews, J.V., Schweger, C.E., Young, S.B., Eds.; Academic Press: New York, NY, USA, London, UK, 1982; pp. 307-326.

24. The Paleolithic of Siberia; Derev'anko, A.P., Shimkin, D.B., Powers, W.R., Eds.; Institute of Archaeology and Ethnography: Novosibirsk, Russia; University of Illinois: Urbana and Chicago, IL, USA, 1998; p. 97 (Okladnikov Cave).

25. Tseitlin, S.M. Geologiia Paleolita severnoi Azii (Geology of the Paleolithic Period in Northern Asia); Nauka: Moscow, Russia, 1979; pp. 84-88 (Strashnaia Cave).

26. Jacobson-Tepfer, E.; Meacham, J.; Tepfer, G. Archaeology and Landscape in the Mongolian Altai; ESRI Press: Redlands, CA, USA, 2010; pp. 82-83.

27. MAIIC. Available online: http://boundless.uoregon.edu/u?/maic,2087 (accessed on 9 July 2013).

28. MAIIC. Available online: http://boundless.uoregon.edu/u?/maic,2124 (accessed on 9 July 2013).

29. MAIIC. Available online: http://boundless.uoregon.edu/u?/maic,600 (accessed on 9 July 2013).

30. MAIIC: Gallery Search: boar.

31. MAIIC. Available online: http://oregondigital.org/u?/maic,2139 (accessed on 9 July 2013).

32. MAIIC. Available online: http://oregondigital.org/u?/maic,2140 (accessed on 9 July 2013).

33. MAIIC. Available online: http://oregondigital.org/u?/maic,1548 (accessed on 9 July 2013).

34. MAIIC. Available online: http://oregondigital.org/u?/maic,2212 (accessed on 9 July 2013). 
35. Dorofeyuk, N.I.; Tarasov, P.E. Vegetation and lake levels in northern Mongolia in the last 12500 years as indicated by data of pollen and diatom analyses. Stratigr. Geol. Correl. 1998, 6, 70-83.

36. Blyakharchuyk, T.A.; Wright, H.E.; Borodavko, P.S.; van der Knaap, W.O.; Ammann, B. Late Glacial and Holocene vegetational changes on the Ulagan high-mountain plateau, Altai Mountains, southern Siberia. Palaeogeogr. Palaeoclimatol. Palaeoecol. 2004, 209, 259-279.

37. Tankersley, K.B.; Kuzmin, Y.V. Patterns of cultural change in eastern Siberia during the Pleistocene-Holocene transition. Quat. Int. 1998, 49, 129-139.

38. Blyakharchuyk, T.A.; Wright H.E.; Borodavko, P.S.; van der Knaap W.O.; Ammann B. Late Glacial and Holocene vegetational changes on the Ulagan high-mountain plateau, Altai Mountains, southern Siberia. Palaeogeogr. Palaeoclimatol. Palaeoecol. 2004, 209, 259-279.

39. Huang, W.-W.; Hou, Y.-M. A perspective on the archaeology of the Pleistocene-Holocene transition in North China and the Qinghai-Tibetan Plateau. INQUA Elsevier Sci. 1998, 49-50 117-127.

40. Tarasov, P.E.; Jolly, D.; Kaplan, J.O. A continuous Late Glacial and Holocene record of vegetation changes in Kazakhstan. Palaeogeogr. Palaeoclimatol. Palaeoecol. 1997, 136, 281-292.

41. Tang, C.; Gai, P. Upper Paleolithic cultural traditions in north China. Adv. World Archaeol. 1986, 5, 339-364.

42. Kuzmin, Y.V. Extinction of the woolly mammoth (Mammuthus primigenius) and woolly rhinoceros (Coelodonta antiquitatis) in Eurasia: Review of chronological and environmental issues. Boreas 2010, 39, 247-261.

43. Guthrie, R.D. Origin and causes of the mammoth steppe: A story of cloud cover, woolly mammal tooth pits, buckles, and inside-out Beringia. Quat. Sci. Rev. 2001, 20, 549-574.

44. Vartanyan, S.L.; Garutt, V.E.; Sher, A.V. Holocene dwarf mammoths from Wrangel Island in the Siberian Arctic. Nature 1993, 362, 337-340.

45. MAIIC: Gallery search: moose.

46. Janz, L.; Elston, R.G.; Burr, G.S. Dating North Asian surface assemblages with ostrich eggshell: Implications for palaeolecology and extirpation. J. Archaeol. Sci. 2009, 36, 1-8.

47. Kurochkin, E.N.; Kuzmin, Y.V.; Antoshchenko-Olenev, I.V.; Zabelin, V.I.; Krivonogov, S.K.; Nohrina, T.I.; Lbova, L.V.; Burr, G.S.; Cruz, R.J. The timing of ostrich existence in Central Asia: AMS 14C age of eggshells from Mongolia and southern Siberia (a pilot study). Nucl. Instrum. Methods Phys. Res. 2010, 268, 1091-1093.

48. Tseitlin, S.M. Geologiia Paleolita severnoi Azii (Geology of the Paleolithic Period in Northern Asia); Nauka: Moscow, Russia, 1979; pp. 77-84.

49. Okladnikov, A.P. Tsentral'noasiatiskii ochag pervobytnogo iskusstva (The Central Asian Hearth of Earliest Art); Nauka: Novosibirsk, Russia, 1972.

50. Novgorodova, E.A. Mir petroglifov Mongolii (The World of Mongolian Petroglyphs); Nauka: Moscow, Russia, 1984; p. 36.

51. Novgorodova, E.A. Drevniaia Mongoliia (Ancient Mongolia); Nauka: Moscow, Russia, 1989; pp. 52-53. 
52. Jang Seogho et al. Mongolyn baruun khoid aimgiin khadny zurag (Petroglyphs from northwestern Mongolia); Northeast Asian History Foundation and Institute of Archaeology: Seoul, Korea; Mongolian Academy of Sciences: Ulaanbaatar, Mongolia, 2009; pp. 388-389.

53. Jang Seogho et al. Mongolyn Gov'-Altain khadny zurag (Petroglyphs from Gov'-Altai, Mongolia); Northeast Asian History Foundation: Seoul, Korea; Institute of Archaeology, Mongolian Academy of Sciences: Ulaanbaatar, Mongolia, 2008; pp. 366-379.

54. Molodin, B.I.; Cheremisin, D.V. Drevneishie naskal'nye izobrazheniia ploskogor'ia Ukok. (Oldest Rock Art from the Ukok Plateau); Nauka: Novosibirsk, Russia, 1999.

55. Molodin, B.I.; Cheremisin, D.V. Drevneishie naskal'nye izobrazheniia ploskogor'ia Ukok. (Oldest rock art from the Ukok Plateau); Nauka: Novosibirsk, Russia, 1999; Figures 23, 32 and 37.

* MAIIC: Mongolian Altai Inventory Image Collection. University of Oregon. (http://boundless.uoregon.edu/digcol/maic/).

(C) 2013 by the author; licensee MDPI, Basel, Switzerland. This article is an open access article distributed under the terms and conditions of the Creative Commons Attribution license (http://creativecommons.org/licenses/by/3.0/). 